\title{
Physicochemical and microstructural properties of composite edible film obtained by complex coacervation between chitosan and whey protein isolate
}

\author{
Loleny Tavares $^{\mathrm{a}, \mathrm{b}}$, Hiléia K.S. Souza ${ }^{\mathrm{a}, 1,{ }^{* *}}$, Maria Pilar Gonçalves ${ }^{\mathrm{a}}$, Cristina M.R. Rocha ${ }^{\mathrm{a}, \mathrm{c}, *}$ \\ ${ }^{\text {a }}$ REQUIMTE-LAQV, Faculdade de Engenharia, Universidade do Porto, Rua Dr. Roberto Frias, 4200-465, Porto, Portugal \\ ${ }^{\mathrm{b}}$ Institute of Food Science and Technology, Federal University of Rio Grande do Sul, Av. Bento Gonçalves, No. 9500, CEP 91501970, Porto Alegre, RS, Brazil \\ ${ }^{c}$ CEB - Centre of Biological Engineering, University of Minho, Campus de Gualtar, 4710-057, Braga, Portugal
}

\section{A R T I C L E I N F O}

\section{Keywords:}

Whey protein isolate

Chitosan

Edible films

Complex coacervation

\begin{abstract}
A B S T R A C T
The aim of this work was to study the potential application of edible films obtained by complex coacervation promoted by the electrostatic interactions between positively charged chitosan $(\mathrm{CH}) 3 \%(\mathrm{w} / \mathrm{w})$ and negatively charged whey protein isolate (WPI) $3 \%(\mathrm{w} / \mathrm{w})$. Preliminary assays of turbidimetry were made in order to find the optimal CH-to-WPI mass ratio for the complex coacervation. The maximum turbidity was obtained in the CH:WPI mass ratio of 0.1:1 (w/w). The dispersions of $\mathrm{CH} / \mathrm{WPI}$ (both at 3\%(w/w)), WPI 5\% (w/w) and $\mathrm{CH} 3 \%(\mathrm{w} / \mathrm{w})$ were analyzed by Cryo-scanning electron microscopy (Cryo-SEM) and the micrograph of $\mathrm{CH} / \mathrm{WPI}$ coacervate presented a more compact network structure than dispersions of individual biopolymers. The composite CH/WPI films were prepared, characterized and their performance and physicochemical properties were compared with those of CH or WPI films, in terms of water vapor permeability (WVP), mechanical properties, solubility, sorption isotherms, optical properties, scanning electron microscopy (SEM) imaging, Fourier-transform infrared spectroscopy (FTIR) and differential scanning calorimetry (DSC). Results revealed that the incorporation of small amounts of $\mathrm{CH}$ in the matrix of WPI led to form a composite film with higher tensile strength, lower deformation, malleability, flexibility, solubility and WVP in comparison to the mono-component WPI and $\mathrm{CH}$ films. The $\mathrm{CH}$ incorporation resulted in a decrease in equilibrium moisture content of the CH/WPI film and the GuggenheimAnderson-de Boer (GAB) model of sorption data indicated isotherms of type II. All the films presented a homogeneous structure, color transparency, which is desired in food applications and packaging technology.
\end{abstract}

\section{Introduction}

The low plastics rate of degradation and their consequent accumulation in the environment has given rise to serious ecological problems and many debates in recent times (Lippolis et al., 2017; Luyt \& Malik, 2019). The global annual production of plastics is expected to reach 330 million tonnes in 2020, and approximately $20 \%$ of this production is used in packaging manufacture in the food industry due to the plastics durability, design flexibility, lightness and low price (Ferreira, Alves, \& Coelhoso, 2016; Hosseini \& Gómez-Guillén, 2018). Edible films or coatings have been studied as potential alternatives for plastic packaging due to their biodegradability, renewable and non-toxic properties
(Alizadeh-Sani, Ehsani, Moghaddas Kia, \& Khezerlou, 2019; Cazón, Velazquez, Ramírez, \& Vázquez, 2017). Though the final aim is not to fully replace traditional non-biodegradable plastics, as there are still many hurdles to be overcome, the use of edible films with friendly polymers may help to lowering the environmental pollution and simultaneously increase the shelf-life and quality of food product (Hosseini e Gómez-Guillén, 2018). The biopolymers used in the formulation of edible films are by-products derived from renewable agricultural resources or industrial by-products (Salgado, Ortiz, Musso, Di Giorgio, \& Mauri, 2015). Edible films are classified into three categories: a) hydrocolloids that include proteins (whey protein, casein, gelatin, wheat gluten, soy protein, and so on) and polysaccharides (alginates,

\footnotetext{
* Corresponding author. CEB - Centre of Biological Engineering, University of Minho, Campus de Gualtar, Braga, 4710-057, Portugal.

** Corresponding author. REQUIMTE-LAQV, Faculdade de Engenharia, Universidade do Porto, Rua Dr. Roberto Frias, Porto, 4200-465, Portugal.

E-mail addresses: hileia.souza@fc.up.pt (H.K.S. Souza), cmrochainv@gmail.com (C.M.R. Rocha).

1 REQUIMTE-LAQV, Departamento de Química e Bioquímica, Faculdade de Ciências, Universidade do Porto, Rua do Campo Alegre, 687, 4169-007, Porto, Portugal.
} 
cellulose and derivatives, starch, chitosan, among others) (Kaewprachu \& Rawdkuen, 2016); b) lipids (waxes, acylglycerols, and fatty acids) (Dehghani, Hosseini, \& Regenstein, 2018); and c) composites (mixtures containing two or more components in order to produce films with improved physicochemical properties) (Salgado et al., 2015).

Biodegradable films are thin layers of edible biodegradable polymers that can be applied to the food stuff (e.g food packaging), to reduce the rate of oxygen absorption, migration of lipids, gasses and aromas, and to prevent the development of microorganisms during storage (Cazón et al., 2017; Tharanathan, 2003). Edible films with functional agents such as antimicrobials, antioxidants and enzymes have also been used to improve the shelf life and quality of the food products (Tavassoli-Kafrani, Shekarchizadeh, \& Masoudpour-Behabadi, 2016).

According to literature, edible films can be formed by three mechanisms: simple coacervation, complex coacervation and gelation or thermal coagulation (Kester \& Fennema, 1986). The complex coacervation results from electrostatic interactions between oppositely charged polysaccharides and proteins, leading to the formation of one phase enriched in both polymers and another enriched in solvent (Rocha, Souza, Magalhães, Andrade, \& Gonçalves, 2014). The complex formation is influenced by different physicochemical parameters, such as $\mathrm{pH}$, total biopolymers concentration, ionic strength of medium, biopolymers mixing ratio, temperature, and agitation time (Schmitt \& Turgeon, 2011).

Chitosan $(\mathrm{CH})$ is a natural polycationic polysaccharide obtained from the alkaline deacetylation of chitin at high temperatures (above $80{ }^{\circ} \mathrm{C}$ ) (Muxika, Etxabide, Uranga, Guerrero, \& de la Caba, 2017). CH is composed of $\beta$-(1-4)-linked D-glucosamine and N-acetyl-d-glucosamine randomly distributed (Tavares \& Noreña, 2019). The unique properties of $\mathrm{CH}$, such as biodegradability, non-toxicity, biocompatibility and anti-fungal properties make it suitable for edible film formulations and other different applications (Mujtaba et al., 2019; Tavares \& Noreña, 2019). CH also stands out of others biopolymers for presenting positive charge at biological $\mathrm{pH}$, while most of the polysaccharides are negatively charged under the same conditions, which allows complex coacervation by electrostatic interactions with a wide range of proteins (Tavares, Barros, Vaghetti, \& Noreña, 2019; Tavares \& Noreña, 2019).

Whey protein isolate (WPI) is a globular protein mixture obtained from cheese and casein manufacture, with a high content of hydrophobic, sulfhydryl groups inside the native globular structure and high proportion of surface hydrophilic groups (Zhang et al., 2016). WPI is used as a food ingredient due to its nutritional value, gelation capacity, and viscosity (Livney, 2010; Tavares et al., 2019). The films obtained from WPI are characterized by transparency, flexibility, lack of odor and taste, favoring its acceptance by consumers (Bourtoom, 2008; Ramos et al., 2013).

As mentioned before, composites films have been used to deliver complementary functional properties to the films over the individual biopolymer properties. For instance, the $\mathrm{CH} / \mathrm{WPI}$ system was studied by Ferreira, Nunes, Delgadillo, and Silva (2009). The authors used conditions where both biopolymers were positively charged. Di Pierro et al. (2006) studied films using dispersions of chitosan-whey protein at $\mathrm{pH}$ 5.0. However, the $\mathrm{pH}$ value was near the isoelectric point, pI, of WPI (4.5-5.5) and the global charge of WPI was neutral, not allowing significant electrostatic interactions between $\mathrm{CH}$ and WPI. Jiang et al. (2016) used chemically modified $\mathrm{CH}$ and crosslinking to improve the properties of the composite $\mathrm{CH} / \mathrm{WPI}$ film. The mixture of $\mathrm{CH}$ and WPI has been studied in other applications, such as encapsulation and edible film formulations (Bastos, Gonçalves, Andrade, Araújo, \& Rocha Leão, 2012; Di Pierro et al., 2006; Di Pierro, Sorrentino, Mariniello, Giosafatto, \& Porta, 2011; Ferreira, Nunes, Delgadillo, \& Lopes-da-Silva, 2009; Kurek, Galus, \& Debeaufort, 2014; Souza, Bai, Gonçalves, \& Bastos, 2009; bib_Tavares_et_al_2019Tavares et al., 2019; Tavares \& Noreña, 2019, 2021). However, to our knowledge, the use for film production of $\mathrm{CH} /$ WPI mixtures obtained by the mechanism of complex coacervation was not reported. Therefore, the main objectives of this study were: a) to optimize the conditions to promote the complex coacervation between positively charged chitosan $(\mathrm{CH})$ and negatively charged whey protein isolate (WPI); and b) to study the influence of the mechanism of complex coacervation on the physicochemical properties of the $\mathrm{CH} / \mathrm{WPI}$ film when compared to the properties of the mono-component $\mathrm{CH}$ and WPI films. For comparison purposes, film formation with thermally induced denaturation of whey proteins was also considered, as it is the most common method used in literature for WPI-based films.

\section{Material and methods}

\subsection{Materials and reagents}

A commercial whey protein isolate (WPI, LACTOPRODAN DI-9224) was purchased from Arla Foods Ingredients Ambh (Denmark). Chitosan (CH) with a degree of deacetylation (DD) of $92 \%$ was obtained from Primex (Siglufjordur, Iceland). Sodium acetate trihydrate $\left(\mathrm{CH}_{3} \mathrm{COO}\right.$ $\left.\mathrm{Na} \cdot 3 \mathrm{H}_{2} \mathrm{O}\right)(99.5 \%)$ and glacial acetic acid $\left(\mathrm{CH}_{3} \mathrm{COOH}\right)$ were purchased from Merck. Purified water, produced by a Milli-Q filtration system, was used for the preparation of all solutions.

\subsection{Solutions preparation}

The acetate buffer solutions were prepared by dissolving appropriate amounts of $\mathrm{CH}_{3} \mathrm{COOH}$ and $\mathrm{CH}_{3} \mathrm{COONa}$ in water and keeping the ionic strength equal to $0.100 \mathrm{~mol} \cdot \mathrm{L}^{-1}$. The $\mathrm{CH}(0.1$ and $3 \%(\mathrm{w} / \mathrm{w}))$ solutions were prepared by dissolving weighted amounts of the respective solid sample in acetate buffer at $\mathrm{pH} 5.5$, whereas the WPI $(0.1$ and $3 \%(\mathrm{w} / \mathrm{w}))$ solutions were prepared at $\mathrm{pH}$ 6.0. The final $\mathrm{pH}$ was adjusted with $\mathrm{CH}_{3} \mathrm{COOH}$ or $\mathrm{NaOH}$, when needed. The $\mathrm{CH}$ solutions were centrifuged at $13000 \mathrm{rpm}$ for $15 \mathrm{~min}$ in order to remove impurities. CH and WPI solutions were stirred for $4 \mathrm{~h}$ and subsequently stored in the refrigerator for $24 \mathrm{~h}$ until complete solubilization.

\subsection{Coacervation conditions (preliminary assays)}

\subsubsection{Turbidity measurements}

Turbidity measurements were performed according to the method described by Bastos et al. (2010), with minor modifications. Aliquots $(2-200 \mu \mathrm{L})$ of $\mathrm{CH} 0.1 \%(\mathrm{w} / \mathrm{w})$ solution at $\mathrm{pH} 5.5$ were added stepwise to $0.9 \mathrm{~mL}$ of WPI $0.1 \%(\mathrm{w} / \mathrm{w})$ solution at $\mathrm{pH}$ 6.0. The turbidity (or optical dispersion, O.D.) of CH/WPI solutions was measured using an AGILENT $8453 \mathrm{UV}-$ visible spectrophotometer, at a wavelength of $400 \mathrm{~nm}$. The influence of $\mathrm{CH}$ :WPI ratio $(\%$ weight $(\mathrm{w} / \mathrm{w})$ ) was determined in triplicate.

\subsubsection{Cryo-scanning electron microscopy (Cryo-SEM)}

The observation and analysis of the microstructure of CH/WPI (both at $3 \%(\mathrm{w} / \mathrm{w}))$, WPI $5 \%(\mathrm{w} / \mathrm{w})$ and $\mathrm{CH} 3 \%(\mathrm{w} / \mathrm{w})$ solutions were performed at CEMUP, Porto, Portugal as previously described by Rocha et al. (2014). The solutions of biopolymers were frozen in slushy nitrogen $\left(-210{ }^{\circ} \mathrm{C}\right)$ and then transferred to an ALTO 2500 Cryo preparation chamber at $-150{ }^{\circ} \mathrm{C}$. The resulting frozen samples were fractured and the ice formed was removed by sublimation at $-90^{\circ} \mathrm{C}$ for $1.5 \mathrm{~min}$. The samples were coated with a sputtered Au-Pd thin film at $-150^{\circ} \mathrm{C}$ for 40 $\mathrm{s}$, from a sputter head using ultrapure Argon gas. Analyses were performed at $-150{ }^{\circ} \mathrm{C}$ in a JEOL JSM $6301 \mathrm{~F}$ scanning electron microscope (Japan) equipped with a Gatan ALTO 2500 Cryo preparation chamber using an accelerating voltage of $15 \mathrm{kV}$ and working distances of $15 \mathrm{~mm}$.

\subsubsection{Preparation of $\mathrm{CH}$, WPI and $\mathrm{CH} / \mathrm{WPI}$ films}

$\mathrm{CH}$ films were prepared using the $\mathrm{CH} 3 \%(\mathrm{w} / \mathrm{w})$ solution. WPI films were prepared using the WPI solution prepared at $5 \%(w / w)$ instead of $3 \%(\mathrm{w} / \mathrm{w})$, since the films obtained from WPI $3 \%(\mathrm{w} / \mathrm{w})$ appeared shrunk, curled and were difficult to remove from the Petri dish, thus 
hampering their characterization. WPI $5 \%(\mathrm{w} / \mathrm{w})$ film forming solutions were used to produce films at pH 6 (WPI-6) and pH 7 (WPI-7). For WPI6 , the film-forming solution was prepared without any heat treatment. Nevertheless, for WPI-7, the films were obtained by a gelation mechanism described by Kurek et al. (2014). Briefly, the film-forming solution was prepared in distilled water at $\mathrm{pH} 7.0$, being the solution submitted to an heat treatment at $70{ }^{\circ} \mathrm{C}$ during $20 \mathrm{~min}$, which induces unfolding of the globular whey proteins and exposure of internal sulfhydryl and hydrophobic groups, promoting cross-linking process via intermolecular disulfide bonds (Pérez-Gago, Nadaud, \& Krochta, 1999).

For the $\mathrm{CH} / \mathrm{WPI}$ film, a $\mathrm{CH} 3 \%(\mathrm{w} / \mathrm{w})$ solution was added to WPI $3 \%$ (w/w) solution according the optimum CH:WPI ratio determined by turbidity measurements. The CH/WPI stock solution thus obtained was agitated at $200 \mathrm{rpm}$ for $20 \mathrm{~min}$. Thereafter, two phases were formed: a solvent-rich phase (supernatant) and a dense biopolymer-rich phase (CH/WPI coacervate phase). The supernatant was discarded and the precipitated $\mathrm{CH} /$ WPI coacervate was recovered. The coacervate dry weight was determined using a vacuum oven at $105^{\circ} \mathrm{C}$ for $24 \mathrm{~h}$. Then, the appropriate amount of plasticizer (glycerol) was added (30 wt $\%$ of plasticizer per dry weight of $\mathrm{CH} /$ WPI coacervate) to the $\mathrm{CH} /$ WPI coacervate. The mixture was then homogenized in a homogenizer (UltraTurrax $\AA$, IKA) at $5000 \mathrm{rpm}$ for $5 \mathrm{~min}$, followed by sonication for $15 \mathrm{~min}$, in order to remove small bubbles formed upon stirring. Finally, a fixed amount $(30 \mathrm{~g})$ of the mixture was spread on polyoxyethylene methylene (POM) Petri dishes and allowed to dry in a climatic test chamber at $25^{\circ} \mathrm{C}$ and $40 \%$ of relative humidity for $24 \mathrm{~h}$.

The WPI-6, WPI-7 and CH films were obtained following the same procedure described for the $\mathrm{CH} / \mathrm{WPI}$ films, namely using the same plasticizer content ( $30 \mathrm{wt} \%$ of glycerol), the same amount $(30 \mathrm{~g}$ ) of filmforming solution to spread on Petri dishes and the same drying method.

\subsection{Films characterization}

\subsubsection{Thickness measurement}

The thickness $(x)$ for each type of film was evaluated using a thickness measuring device (Absolute Digimatic Indicator, model ID-F150, Mitutoyo Co., Japan) with a resolution of $1 \mu \mathrm{m}$, and the measurements were performed at five random positions.

\subsubsection{Mechanical properties}

The tensile strength and elongation at break were determined using a TAXT2 Texture Analyzer and the analyses were performed according to the standard method ASTM D 882-89. Films strips $8.0 \mathrm{~cm}$ long and 1.5 $\mathrm{cm}$ wide were fixed on the grips and subjected to extensional deformation with the application of a displacement rate of $50 \mathrm{~mm} / \mathrm{min}$ until their rupture. Six replicates were performed in each case.

\subsubsection{Water vapor permeability}

Measurement of the water vapor transmission rate (WVTR) and calculation of the water vapor permeability (WVP) were performed gravimetrically based on ASTM E96-95 method previously described in ASTM (1995). The samples were cut in a circular form with $80 \mathrm{~mm}$ diameter and placed in each sealed cell containing anhydrous calcium chloride $(\mathrm{RH}=2 \%)$. The cells were weighed periodically, and the water vapor permeability (WVP) in $\mathrm{g} \mathrm{m}^{-1} \mathrm{~s}^{-1} \mathrm{~Pa}^{-1}$, of each film was determined according to Eq. (1):

$W V P=\frac{\Delta m \cdot x}{A \cdot \Delta t \cdot \Delta P}$

where $\Delta m$ is the weight gain (g), $x$ is the film thickness, $A$ is the area of exposed film $\left(0.003 \mathrm{~m}^{2}\right)$ exposed for a time $\Delta t$ (s) to a water vapor partial pressure differential $\Delta P(\mathrm{~Pa})$. The water vapor permeability of each film was determined in triplicate.

\subsubsection{Solubility in water}

The water solubility of the films was tested according to a similar procedure elaborated by Rhim, Gennadios, Weller, Carole, and Hanna (1998). The samples were cut into $2.5 \times 2.5 \mathrm{~cm}$ strips. These specimens were dried in an oven at $105{ }^{\circ} \mathrm{C}$ for $24 \mathrm{~h}$, weighed $\left(m_{i}\right)$, and inserted, for $24 \mathrm{~h}$, into a beaker containing $50 \mathrm{~mL}$ of distilled water, at room temperature. Then, the wet films were placed back in the oven to dry at $105{ }^{\circ} \mathrm{C}$ for $24 \mathrm{~h}$. Subsequently, they were weighed again to obtain the final weight $\left(m_{f}\right)$. All the procedures were performed in triplicate.

\subsubsection{Sorption isotherms}

The water sorption isotherms were determined gravimetrically as previously described by Sousa et al. (2014). Pieces of films $(2.5 \times 2.5$ $\mathrm{cm}$ ), previously dried in a vacuum oven at $60^{\circ} \mathrm{C}$ for $48 \mathrm{~h}$, were weighed and put into hermetic test chambers containing different saturated aqueous salt solutions at water activities varying between 0.113 and 0.903 , and stored at room temperature The samples were weighed periodically until they reached constant weight (i.e. were considered at equilibrium). Duplicate measurements were performed for each film formulation. The Guggenheim-Anderson-de Boer (GAB) model (Anderson, 1946; Boer, 1968) (Eq. (2)), was used to fit the experimental sorption data.

$X_{e}=\frac{C \cdot k \cdot X_{0} \cdot a_{w}}{\left[\left(1-k \cdot a_{w}\right) \cdot\left(1-k \cdot a_{w}+C \cdot k \cdot a_{w}\right)\right]}$

where $X_{e}$ is the equilibrium moisture content on a dry basis, $X_{0}$ represents the monolayer moisture content (on a dry basis), $C$, Guggenheim constant, is a constant dependent on the water sorption heat in the first and subsequent layers, $k$ is a parameter reflecting the sorption heat of the multilayer as well as the heat of condensation of water vapor, and $a_{w}$ represents water activity.

The experimental sorption data was fitted with Eq. (2), by performing a non-linear estimation using Statistica version 8 software (StatSoft, Tulsa, OK, USA), thus obtaining the corresponding GAB parameters.

\subsubsection{Optical properties}

Optical measurements were performed in a Minolta colorimeter (Minolta CR 400, Tokyo, Japan). The CIELab scale was used to determine values of color difference $(\Delta E)$, luminance $\left(L^{*}\right)$, which is expressed as a percentage (from 0 for black to 100 for white) and ranges of color ( $a^{*}$ and $b^{*}$, where $a^{*}$ ranges from green $(-)$ to red $(+)$ and $b^{*}$ from blue $(-)$ to yellow $(+))$ of each film. The color difference $(\Delta E)$ was calculated according to Eq. (3):

$\Delta E=\sqrt{\left(\mathrm{L}^{*}-\mathrm{L}\right)^{2}+\left(a^{*}-a\right)^{2}+\left(b^{*}-b\right)^{2}}$

where $L, a$, and $b$ represent the standard values of the white calibration plate.

The opacity (\%) of the films was evaluated using a Minolta colorimeter (Minolta CR 400, Tokyo calibrated with a standard white background $\left(Y_{w}\right)$ and a standard black background $\left(Y_{b}\right)$. The opacity values were calculated according to Eq. (4):

Opacity $=\frac{Y_{b}}{Y_{w}} \times 100$

Both color difference $(\Delta E)$ and opacity parameters were measured seven times at different spots of each film.

\subsubsection{Scanning electron microscopy (SEM)}

The analysis of the microstructure of the films was made in an electronic scanning microscope FEI Quanta 400 FEG located in CEMUP (Materials Center at the University of Porto). The samples were fixed on aluminum supports with double-sided carbon tape and coated with a fine Au-Pd layer. The upper surface and the cross section of the films 
were analyzed at an acceleration voltage of $5 \mathrm{kV}$, working distances (WD) between 10.9 and $11.7 \mathrm{~mm}$ and a magnification level of x10000.

\subsubsection{Fourier-transform infrared spectroscopy}

FTIR spectra of the films were acquired using an ALPHA II- Bruker spectrometer (Ettlingen, Germany), with Diamond ATR (Attenuated Total Reflectance), at room temperature. FTIR spectra of films were recorded using the abrasive pad of the ATR accessory, pouring a small piece of sample onto the pad. All spectra were registered between 4000 and $400 \mathrm{~cm}^{-1}$ and collected at a resolution of $4 \mathrm{~cm}^{-1} ; 24$ scans were averaged before Fourier transformation.

\subsubsection{Differential scanning calorimetry}

The thermal properties of $\mathrm{CH}$, WPI-6, WPI-7 and $\mathrm{CH} /$ WPI were evaluated through differential scanning calorimetry (DSC) using a PerkinElmer DSC 6000 equipment. Film samples (approx. $5 \mathrm{mg}$ ) were cooled to $0{ }^{\circ} \mathrm{C}$. Analysis was carried out from $0{ }^{\circ} \mathrm{C}$ to $250{ }^{\circ} \mathrm{C}$ at a heating rate of $10^{\circ} \mathrm{C} \cdot \mathrm{min}^{-1}$, under a nitrogen atmosphere (purge gas flow of 20 $\mathrm{mL} \min ^{-1}$ ).

\subsection{Statistical analyses}

The data were analyzed by Analysis of Variance (ANOVA) and differences between means were analyzed by Tukey's test at a significance level of $P \leq 0.05$, using SAS (version 9.3) software.

\section{Results and discussion}

The results section was divided in two main parts: in the first one, the maximum interaction between $\mathrm{CH}$ and WPI, which is associated with the formation of aggregates suspended in the liquid matrix, was studied aiming to select the best complex coacervation condition to be used in the $\mathrm{CH} /$ WPI film production; in the second part, $\mathrm{CH} /$ WPI films were prepared, characterized and their performance and physicochemical properties were compared with those of WPI or $\mathrm{CH}$ films alone. In addition, the effect of thermally induced denaturation of whey proteins on the mechanical properties and water vapor permeability of WPI based films (WPI-6 and WPI-7) was also evaluated.

\subsection{Characterization of $\mathrm{CH} / \mathrm{WPI}$ coacervate-forming solutions}

\subsubsection{Turbidity measurements}

Though CH/WPI interactions strongly depend on $\mathrm{pH}$, previous works already established the working $\mathrm{pH}$ range for electrostatic interaction to occur in this system: higher than the isoelectric point of the proteins involved (for WPI, as already referred above, between 4.5 and 5.5), and lower than pKa of 6.5 for $\mathrm{CH}$ (Bastos et al., 2010). WPI has amphoteric nature due to the presence of both amino $\left(\mathrm{NH}_{2}\right)$ and carboxyl $(\mathrm{COOH})$ functional groups, while $\mathrm{CH}$ has positive charge at acidic conditions due to its positive amino groups $\left(\mathrm{NH}_{3}^{+}\right)$. Therefore, the working $\mathrm{pH}$ was set at $6.0(\mathrm{pH}>\mathrm{pI}$ of WPI and $\mathrm{pH}<\mathrm{pKa}$ of $\mathrm{CH}$ ), which promotes electrostatic interactions between negative carboxyl groups $\left(\mathrm{COO}^{-}\right)$of WPI and positive amino groups $\left(\mathrm{NH}_{3}^{+}\right)$for $\mathrm{CH}$ (Tavares et al., 2019; Tavares \& Noreña, 2019).

The turbidity was determined at various $\mathrm{CH}$-to-WPI ratios by addition of $\mathrm{CH} 0.1 \%(\mathrm{w} / \mathrm{w})$ aliquots to the WPI solution $0.1 \%(\mathrm{w} / \mathrm{w})$. It was found that, when the $\mathrm{CH}$-to-WPI ratio was increased, the turbidity increased until maximum interaction between $\mathrm{CH}$ and WPI reached a plateau at an O.D. around 1.059, at CH-to-WPI mass ratio of $0.10(\mathrm{w} / \mathrm{w})$ (Fig. 1). The turbidity increased due to clots and coacervate formation containing CH/WPI complexes (Bastos et al., 2010), until the plateau, when $\mathrm{CH}$ molecules are saturated with WPI and no more insoluble complexes are formed. After that, the O.D. remained practically unchanged due to a maximum interaction between the positive charges of $\mathrm{CH}$ and negative charges of WPI (stoichiometrically equal). The maximum interaction remained constant even with the addition of larger amounts of $\mathrm{CH}$, meaning that the formed complexes remained stable. According to Espinosa-Andrews, Sandoval-Castilla, Vázquez-Torres, Vernon-Carter, and Lobato-Calleros (2010), at the point of maximum interaction, the ionized groups of the oppositely charged biopolymers are mutually neutralized, leading to the formation of coacervate as insoluble complex.

The turbidity of the solutions is attributed to the appearance of scattering particles or droplets in the medium, related to the coacervate

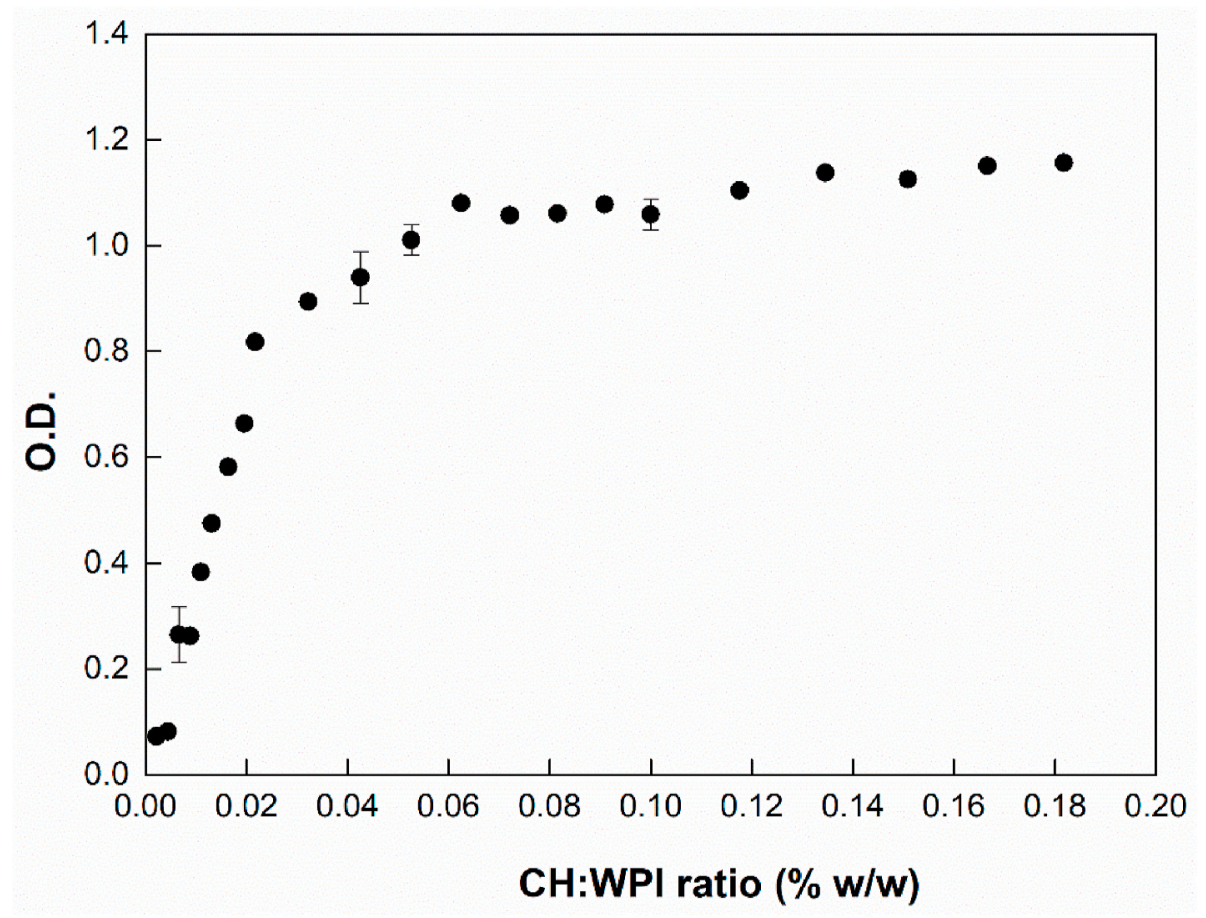

Fig. 1. Influence of CH:WPI mas ratio (\% weight $\mathrm{w} / \mathrm{w})$ on the turbidity of WPI $0.1 \%(\mathrm{w} / \mathrm{w})$ solutions with aliquots $(2-200 \mu \mathrm{L})$ of $\mathrm{CH} 0.1 \%(\mathrm{w} / \mathrm{w})$ solutions. 
formation. Ducel, Richard, Saulnier, Popineau, and Boury (2004) reported values of maximum turbidity of the same order of magnitude $(0.02 \mathrm{~mol} / \mathrm{mol})$ between mixtures of WPI $0.5 \%(\mathrm{w} / \mathrm{w})$ and $\mathrm{CH} 0.4 \%$ $(\mathrm{w} / \mathrm{w})$. However, Tavares and Noreña (2019) determined the coacervation yield of the CH/WPI system by gravimetric analyses and found maximum coacervate yield at CH-to-WPI ratio of $0.2: 1(\mathrm{w} / \mathrm{w})$, instead of $0.1: 1(\mathrm{w} / \mathrm{w})$. Nevertheless, the degree of deacetylation of $\mathrm{CH}(\mathrm{DD}=83$, 94 and 96\%) and the technique used by these authors (gravimetry) were different from those used in the present study (DD $=92 \%$ and turbidimetry, respectively). Different deacetylation degrees and molecular weights may lead to different molecular interactions with WPI molecules (Tavares \& Noreña, 2019). According to the described above, and to guarantee that the chosen parameters are already in the plateau region, $\mathrm{CH} / \mathrm{WPI}$ mass ratio of $0.1: 1(\mathrm{w} / \mathrm{w})$ (slightly above the beginning of the plateau, Fig. 1) was selected for the production of the composite films of $\mathrm{CH} /$ WPI by complex coacervation.

\subsubsection{Cryo-SEM}

The Cryo-SEM technique allows the visualization and morphological characterization of coacervates structure in their native environment before the process of dry-down to films, where substantial structural changes occur. The results from Cryo-SEM are shown in Fig. 2. The different solution composition clearly led to different network structure, mesh, arrangement and bonds in solution, corresponding to different morphologies. The $\mathrm{CH} 3 \%$ (Fig. 2A) showed a continuous and homogeneous network with well-defined but much larger matrix structure. In the case of WPI 5\% (Fig. 2B) the structure is disperse and no network is observed. There was no formation of a homogenous structure. The $\mathrm{CH} /$ WPI coacervate (Fig. 2C) presented a balanced and compact structure, with continuous network and tight net mesh (close to one another), indicating synergistic effects of complex coacervation between $\mathrm{CH}$ and WPI. The compact network structure mainly result due to the electrostatic interactions between $\mathrm{CH}$ and WPI, providing the formation of coacervates with three-dimensional layer-layer stacking (Souza et al., 2009). However, according to Jho, Yoo, Lin, Han, and Hwang (2017), in some systems of complex coacervation the resulting dense coacervate may not present a network with homogeneous phase, but phase separation into a biopolymers complex-rich phase and a bulk-like water microphase, at nanoscale length for phase separation.

The results of the coacervate network structure demonstrated that the electrostatic interactions between $\mathrm{CH}$ and WPI allow reinforcing the molecular structure of $\mathrm{CH} /$ WPI complex. Similar behavior is reported by Rocha et al. (2014), for whey protein/agar insoluble complexes, with whey proteins distributed randomly and homogeneously through the agar gel matrix.

The CH/WPI coacervate produced by complex coacervation showed homogeneous and compact structure and the physicochemical properties of produced films were determined and compared with those of $\mathrm{CH}$ or WPI films alone.

\subsection{Films properties}

\subsubsection{Thickness and mechanical properties}

The thickness is a crucial factor for studying the physical properties of films, since it directly affects others physicochemical properties such WVP or mechanical properties (Khodaei, Oltrogge, \& Hamidi-Esfahani, 2020). The average film thickness $(x)$ measured for the $\mathrm{CH}$, WPI, WPI-D and $\mathrm{CH} /$ WPI films is presented in Table 1 . The highest value was obtained for the $\mathrm{CH} /$ WPI film, which can be correlated with its higher compact structure. The thickness of the WPI-6 films was smaller than WPI-7 films, indicating that the covalent cross-linking promoted by the heat denaturation of the whey proteins allow to increase the thickness.

Edible films with good mechanical properties are essential for food packaging and preservation functions during product transport and storage. The mechanical properties of films are influenced by the nature and chemical structure of film-forming components and structural cohesion (Eghbal et al., 2016; Ramos et al., 2013). The measured values of the tensile strength (TS) and elongation at break $(E)$ are given in Table 1. Tensile strength is related to the mechanical resistance of films associated to the cohesion forces between chains, and elongation at break measures the ability of the films to extend before breaking (Galus \& Lenart, 2013). The tensile strength of $\mathrm{CH} /$ WPI composite films was significantly $(\mathrm{p}<0.05)$ greater than the tensile strength obtained from the mono-component films (WPI-6, WPI-7 and CH). This increase is mainly due to the reinforcement of the WPI matrix with small amounts of incorporated $\mathrm{CH}$, which had significant $(\mathrm{p}<0.05)$ effect on the mechanical parameters of $\mathrm{CH} / \mathrm{WPI}$ films. The electrostatic interaction

Table 1

Thickness $(x)$, Tensile strength (TS), elongation at break $(E A B)$ and water vapor permeability $(W V P)$ for the films composed by $\mathrm{CH} 3 \%(\mathrm{w} / \mathrm{w})$, WPI- 6 and WPI-7 both prepared at $5 \%(\mathrm{w} / \mathrm{w})$, and CH/WPI mass ratio of $0.1: 1(\mathrm{w} / \mathrm{w})^{\mathrm{a}}$.

\begin{tabular}{|c|c|c|c|c|}
\hline \multirow[t]{2}{*}{ Films } & \multirow[t]{2}{*}{$x(\mathrm{~mm})$} & \multicolumn{2}{|c|}{ Mechanical property } & \multirow{2}{*}{$\begin{array}{l}W V P\left(\mathrm{~g} \mathrm{~m}^{-1} \mathrm{~s}^{-1} \mathrm{~Pa}^{-1}\right) \times \\
10^{-9}\end{array}$} \\
\hline & & $E A B(\%)$ & TS (MPa) & \\
\hline $\mathrm{CH}$ & $\begin{array}{l}0.27 \pm \\
0.02^{\mathrm{b}}\end{array}$ & $\begin{array}{l}25.42 \pm \\
4.74^{\mathrm{b}}\end{array}$ & $\begin{array}{l}1.24 \pm \\
0.27^{\mathrm{c}}\end{array}$ & $0.88 \pm 0.07^{c}$ \\
\hline WPI-6 & $\begin{array}{l}0.20 \pm \\
0.01^{\mathrm{d}}\end{array}$ & $\begin{array}{l}42.36 \pm \\
7.89^{\mathrm{a}}\end{array}$ & $\begin{array}{l}0.19 \pm \\
0.05^{\mathrm{d}}\end{array}$ & $1.05 \pm 0.07^{\mathrm{b}}$ \\
\hline WPI-7 & $\begin{array}{l}0.25 \pm \\
0.04^{\mathrm{c}}\end{array}$ & $9.34 \pm 1.71^{c}$ & $\begin{array}{l}2.04 \pm \\
0.31^{\mathrm{b}}\end{array}$ & $1.78 \pm 0.33^{\mathrm{a}}$ \\
\hline $\begin{array}{l}\text { CH/ } \\
\text { WPI }\end{array}$ & $\begin{array}{l}0.35 \pm \\
0.03^{\mathrm{a}}\end{array}$ & $4.60 \pm 0.45^{\mathrm{d}}$ & $\begin{array}{l}3.87 \pm \\
0.46^{\mathrm{a}}\end{array}$ & $1.02 \pm 0.06^{\mathrm{b}}$ \\
\hline
\end{tabular}

a Means with the same letter, in the same column, did not differ significantly ( $\mathrm{p} \leq 0.05$ ), according to the Tukey test.
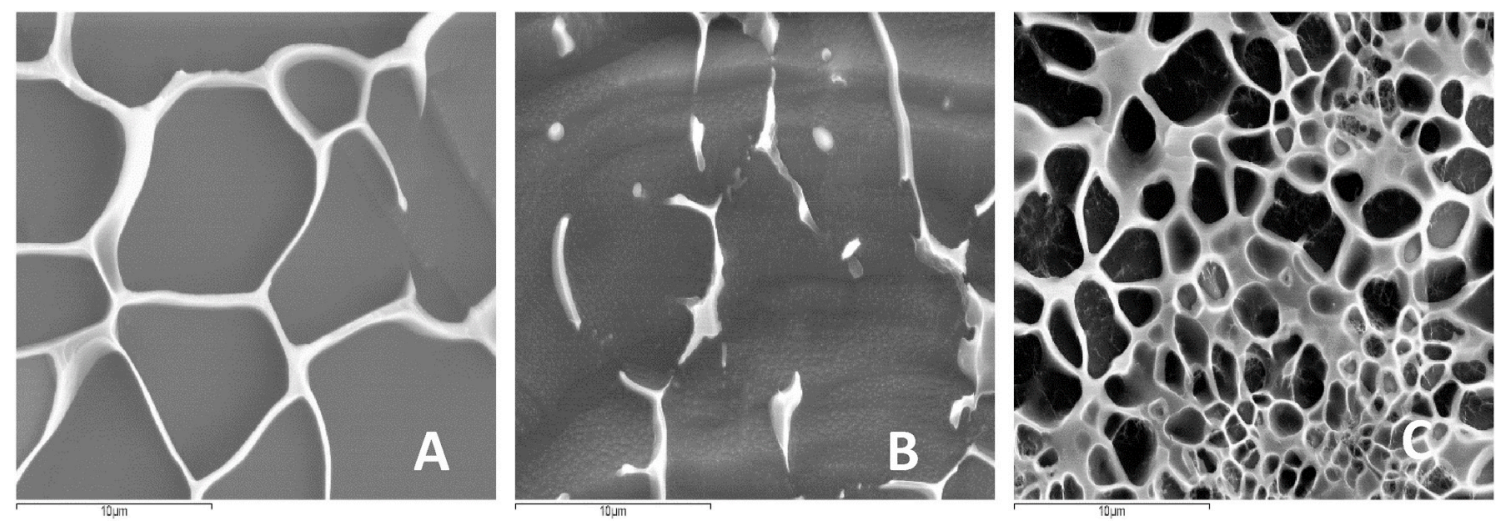

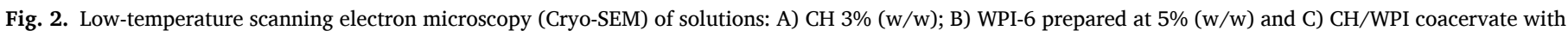
mass ratio of $0.1: 1(\mathrm{w} / \mathrm{w})$. Amplifications of x5000. The accelerating voltage was $15 \mathrm{kV}$ and working distance $15 \mathrm{~mm}$ in all cases. 
between the positively charged $\mathrm{CH}$ (amino groups) and negatively charged WPI (carboxyl groups) improved rigidity and created a stronger network. This also resulted in a stiffer structure with decreased deformation at break, probably due to the lower malleability and flexibility of these films, promoted by the better homogenization and formation of thinner layers due to the electrostatic interaction between $\mathrm{CH}$ and WPI. The TS value achieved for the system of CH/WPI (obtained by the complex coacervation method) was also higher than reported values for the same system where film formation was achieved by other mechanisms, namely: Ferreira et al. (2009) that studied the influence of the protein amount in $\mathrm{CH} / \mathrm{WPI}$ films, and reported that the increasing protein proportion caused decreasing in the elongation at break and tensile strength due to the formation of less cohesive structures. Kurek et al. (2014) also reported CH/WPI values of tensile strength and elongation at break of $0.60 \mathrm{MPa} \pm 1.67$ and $33.90 \pm 6.37 \%$, respectively. In this study reported by Kurek et al. (2014), both biopolymers were positively charged, and there was no electrostatic interactions between them and the complex coacervation did not take place. WPI-7 film showed higher TS and $E A B$ values than WPI- 6 film, indicating that the covalent cross-linking via intermolecular disulfide bonds promoted by globular whey protein denaturation increased the mechanical properties of the WPI based films. These results are mainly influenced by the molecular structure of the produced films, since the WPI-7 films were made of cross-linked protein strands, whereas WPI-6 films have a more random structure in which cohesion is mainly due to hydrogen bonding (bib_Pérez_Gago_et_al_1999Pérez-Gago et al., 1999).

\subsubsection{Water vapor permeability}

The WVP is one of the most important properties of edibles films. The water content present in products influence significantly the change in the rates of deteriorative reactions and WVP reflects the capacity of the film (when applied as package in food protection) to control the transfer of moisture between food and its surrounding (Homez-Jara et al., 2018; Kurek et al., 2014). CH/WPI films showed a better protection barrier for the water vapor when compared to the WPI-7 films produced by gelation mechanism (Table 1). It is expected that $\mathrm{CH} / \mathrm{WPI}$ films present more hydrophobic characteristics due to the canceling of charges promoted by electrostatic interactions, which may limit biopolymer segmental mobility and contribute to reduce the WVP, making the film less permeable to water vapor. The WVP values for $\mathrm{CH} / \mathrm{WPI}$ and WPI- 6 films did not differ significantly ( $p>0.05$ ), which may indicate that WPI had higher influence than $\mathrm{CH}$ in the obtained WVP value for $\mathrm{CH} /$ WPI film. Furthermore, $\mathrm{CH}$ films presented the lower WVP, which may indicate that incorporating of $\mathrm{CH}$ will also decrease WVP of WPI films. In fact, it has been reported that the WVP of CH/WPI films increased with the amount of $\mathrm{CH}$ present due to polymer-polymer interaction (Ferreira et al., 2009). Kurek et al. (2014) reported WVP with values ranging from 0.55 to $3.72 \times 10^{-10} \mathrm{~g} \mathrm{~m}^{-1} \mathrm{~s}^{-1} \mathrm{~Pa}^{-1}$ for CH/WPI films dried in three different relative humidity $(\mathrm{RH})$ gradient conditions $(33-0 \%, 75-30 \%$, and $100-30 \%$ ), respectively. The $\mathrm{RH}=40 \%$ and mechanism of coacervation utilized in our study as well as differences in biopolymers concentration could explain the results' differences. The WPI-7 films showed higher values of WVP than the WPI- 6 films, indicating changes in the molecular structure of the WPI based films. The WVP properties of both $\mathrm{CH}$ and WPI based films have been studied by different authors: Kokoszka, Debeaufort, Lenart, and Voilley (2010) studied the behavior of WPI films with four concentrations of protein at four different RH gradients, and concluded that the WVP values of the films increased with the WPI concentration, except for high RH gradient. Homez-Jara et al. (2018) reported results of WVP for $\mathrm{CH}$ films ranging between $0.27 \times$ $10^{-11} \mathrm{~g} \mathrm{~m}^{-1} \mathrm{~s}^{-1} \mathrm{~Pa}^{-1}$ and $92.2 \times 10^{-11} \mathrm{~g} \mathrm{~m}^{-1} \mathrm{~s}^{-1} \mathrm{~Pa}^{-1}$, and concluded that $\mathrm{CH}$ concentration did not have a consistent effect on the WVP values.

\subsubsection{Solubility}

The water solubility of $\mathrm{CH}$ films was $41.82 \%$, which is higher than the values ranging from 19 to $32 \%$ reported by Homez-Jara et al. (2018) for $\mathrm{CH}$ films with different concentrations $(0.5,1.0$ and $1.5 \%)$ and drying temperatures $\left(2,25\right.$ and $\left.40{ }^{\circ} \mathrm{C}\right)$. de Morais Lima et al. (2017) reported solubility of $22 \%$ for $\mathrm{CH} 1.5 \%$ (w/v) film dried at $38{ }^{\circ} \mathrm{C}$ while 7.6\% was reported by Baron, Pérez, Salcedo, Córdoba, and Sobral (2017) for $\mathrm{CH} 2 \%(\mathrm{w} / \mathrm{v})$ film dried at $30{ }^{\circ} \mathrm{C}$. These differences can be ascribed to differences in the molecular weight and degree of deacetylation of $\mathrm{CH}$ as well as to differences in the $\mathrm{CH}$ concentration and plasticizer content. The hydrophilic characteristic of WPI-6 films favored their interaction with $\mathrm{OH}$ water groups resulting in swelling and total solubility in water, which was also reported by (Ferreira et al., 2009). Gounga, Xu, and Wang (2007) reported solubility of $50.58 \%$ for WPI films prepared by gelation mechanism ( $\mathrm{pH} 7$ and denaturation at $90{ }^{\circ} \mathrm{C}$ for $30 \mathrm{~min}$ ). This relatively low solubility was ascribed to the high interaction between hydrophobic regions and existence of intermolecular disulfide bonds promoted by heat treatment. This effect of protein denaturation by heat treatment on the solubility of WPI films was reported by Silva, Mauro, Gonçalves, and Rocha (2016). These authors obtained solubility of 62.04 and $59.97 \%$ for films made with two different heat treatments on the film forming solutions: heating until $75{ }^{\circ} \mathrm{C}$ and heating until $75{ }^{\circ} \mathrm{C}$ and keeping at $75{ }^{\circ} \mathrm{C}$ for $10 \mathrm{~min}$, respectively.

The CH/WPI films showed low solubility in water due to the elimination of charges on their surface. This result indicate the formation of films with more hydrophobic nature, with low interactions between surface adsorption sites and water molecules. The solubility of $\mathrm{CH}$ films was significantly $(\mathrm{p}<0.05)$ higher than the solubility of $\mathrm{CH} / \mathrm{WPI}$ films. Differences in surface charge (protonated amine groups in $\mathrm{CH}$ and null charge resulting from electrostatic interactions in $\mathrm{CH} / \mathrm{WPI}$ films) may explain this result. The complex coacervation between $\mathrm{CH}$ and WPI resulted in $\mathrm{CH} /$ WPI films with low affinity to interact with water molecules, which is beneficial in cases where product integrity and water resistance are desired. This is a major advantage, as high solubility is usually a significant drawback in the industrial application of hydrocolloid-based films.

\subsubsection{Sorption isotherms}

Sorption isotherms provide significant information on how the films will behave when exposed to different humidity conditions. The moisture sensitivity of films was evaluated at $25^{\circ} \mathrm{C}$, over a wide range of $\mathrm{a}_{\mathrm{w}}$. Experimental sorption data are presented in Fig. 3.

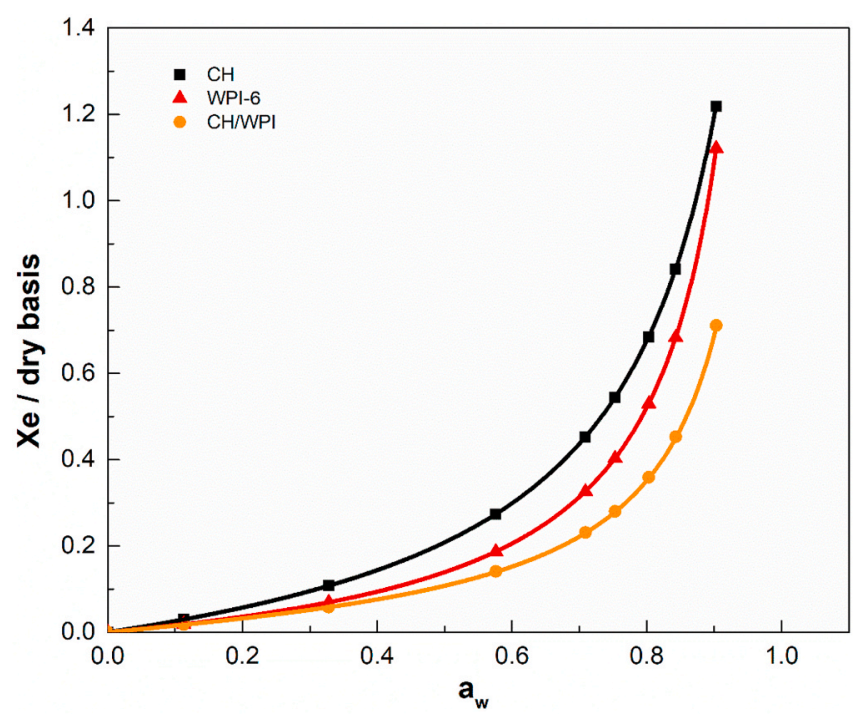

Fig. 3. Equilibrium moisture content $\left(X_{e}\right)$ vs water activity $\left(\mathrm{a}_{\mathrm{w}}\right)$ of experimental sorption data at $25{ }^{\circ} \mathrm{C}$ for the films composed by $\mathrm{CH} 3 \%$ (w/w) (squares), WPI- 6 prepared at $5 \%(\mathrm{w} / \mathrm{w})$ (triangles) and $\mathrm{CH} / \mathrm{WPI}$ coacervate with mass ratio of 0.1:1 (w/w) (circles), with the respective fits using the GAB model (Eq. (2)). 
The equilibrium moisture content, $X_{e}$, increased slowly with increasing $a_{w}$ up to around 0.7. For $a_{w}>0.7$, a steep increase of $X_{e}$ was observed for all films studied (Fig. 3).

The higher solubility, water affinity and water retention of $\mathrm{CH} 3 \%$ $(\mathrm{w} / \mathrm{w})$ and WPI $5 \%(\mathrm{w} / \mathrm{w})$ films resulted in higher $X_{e}$, at a given $a_{w}$, when compared to $\mathrm{CH} /$ WPI film (Fig. 3).

Experimental sorption data was fitted to the GAB model (Eq. (2)). Sigmoid curves, typical of hydrophilic materials, were obtained in all cases (Fig. 3). Overall, a suitable adjustment of the experimental data is obtained, as suggested by the good correlation coefficients $\left(\mathrm{R}^{2}>0.99\right)$ and range of $k$ values $(0<k<1)$ (Sousa et al., 2014) (Table 3).

The amount of water retained at the primary sorption sites of the films was quantified by the monolayer moisture content, $X_{O}$ (on a dry basis) (Table 3). This parameter is related to the composition and chemical structure of each film. The estimated values were higher for pure WPI (0.217) and $\mathrm{CH}(0.137)$ films. $\mathrm{CH} /$ WPI film presented the lowest value (0.089), suggesting less available bonding sites at the monolayer, probably due to the lower hydrophilicity and null surface charge resulting from electrostatic interactions between WPI and $\mathrm{CH}$. The $X_{0}$ values for $\mathrm{CH}$ films are in accordance with the results reported by Souza, Campiña, Sousa, Silva, and Gonçalves (2013), where the values of $X_{0}$ was influenced by the interstitial space existing in the matrices of the films, which increased the rate of diffusion of the water into the monolayer. The parameter $C$, related to the energy difference between adsorption in the form of a monolayer and/or in several multilayers, can be used to quantify the strength of the established bonds between the water molecules and the hydrophilic sites at the monolayer of the polymeric film: the greater the $C$ value, the stronger the bonds (Xiao, Lim, \& Tong, 2012).

C is higher for the CH/WPI films (1.697; Table 3). Adsorption of a monolayer is favored with respect to a larger multilayer formation (stronger bonds are formed), resulting from mixing the two biopolymers (bib_Silva_et_al_2016Silva et al., 2016). For $\mathrm{CH}$ and WPI films, $C$ was lower (1.183 and 1.095, respectively) than for $\mathrm{CH} /$ WPI film. The higher value of $C$ for WPI film, relative to $\mathrm{CH}$ film, suggests that the interaction at the primary sorption sites was stronger in the former case. For all the films studied, the $k$ range values, $0<k<1$ (Table 3), indicates that the water in the upper layers was less structured than pure water (Xiao et al., 2012). This also reflects the solubility and WVP of the films. Overall, films behavior towards water is the result of the net contribution of different factors such as the surface affinity of the film towards water, the size of the films pores and the affinity of the inner films to water, not always working towards the same direction. For instance, in the first case the effect on WVP is positive (the highest affinity towards water the higher WVP would be), but in the last case it may be the opposite (as moving through the film is more difficult due to higher affinity of hydrophilic structures towards water). Similarly, though the values of $X_{O}$ are significantly lower for the CH/WPI film, suggesting lower interaction at the primary layer sites and lower interstitial space available; the $C$ value are considerably higher, suggesting favored adsorption of a monolayer when compared to a larger multilayer formation, meaning that water molecules not bonded to the monolayer will be able to move through the film. This results in a WVP slightly higher than for $\mathrm{CH}$ films and equivalent to WPI-6 films.

\subsubsection{Color}

The color attributes hold a prime role in product appeal and consumer acceptability (Ramos et al., 2013). All the films were visually homogenous and semi-transparent (Fig. 4). The incorporation of $\mathrm{CH}$ into WPI matrix resulted in more yellowish $\mathrm{CH} /$ WPI films with positive $b^{*}$ value (Table 2). The results of color parameters indicated that $\mathrm{CH}$ had higher influence than WPI in the color parameters of the CH/WPI films. The color change in CH/WPI films could be attributed to the original color of $\mathrm{CH}$ that had a slightly yellow appearance (Ojagh, Rezaei, Razavi, \& Hosseini, 2010) and/or due to the stronger network and coacervation mechanism. According to Ebrahimi, Koocheki, Milani, and Mohebbi (2016), the amount and type of interactions between polysaccharide and protein may change the films' color properties.

The films total color difference $(\Delta \mathrm{E})$ was not significantly different ( $p<0.05$ ). The less transparent staining of the composite films was due to the yellowish color of $\mathrm{CH}$. In fact, the opacity values are similar ( $\mathrm{p}>$ 0.05 ) for $\mathrm{CH} / \mathrm{WPI}$ films and $\mathrm{CH}$ films. Furthermore, though differences are statistically significant for WPI films, all films were visually transparent. The color of the composite films is in accordance with other studies reported in literature with high values of $L^{*}$ and variation of $a^{*}$ and $b^{*}$ parameters (Chillo et al., 2008; Córdoba \& Sobral, 2017; Kurek et al., 2014).

\subsubsection{Film microstructure}

The scanning electron microscopy (SEM) technique was used to study the film microstructure, and existence of possible gaps and cracks in their structures. SEM images of films surface are represented in Fig. 5A (CH), Fig. 5B (WPI-6) and Fig. 5C (CH/WPI), and the films crosssection are represented in Fig. 5D (CH), Fig. 5E (WPI-6) and Fig. 5F (CH/ WPI). For the SEM images of films surface, the structure of the surface of $\mathrm{CH} /$ WPI is dense, cohesive and homogeneous, probably due to the incorporation of $\mathrm{CH}$ in the polymer matrix of the WPI. Unlike the results reported by Ferreira et al. (2009), the samples didn't display the phase segregation typical of WPI heat-gelled systems, one phase rich in $\mathrm{CH}$ and other rich in WPI, confirming the thermodynamic compatibility between this biopolymers promoted by complex coacervation. All the films sowed structure with some heterogeneity and roughness. However, when compared $\mathrm{CH} / \mathrm{WPI}$ film with the $\mathrm{CH}$ and WPI-6 films, the latter showed opaque zones in their structures due essentially to the formation of small, non-dissoluble air bubbles. This result is consistent with the formation of $\mathrm{CH}$ and WPI films with poor mechanical properties and more fragile and weak microstructure. Talón et al. (2017) showed similar results for $\mathrm{CH}$ films, which presented a heterogeneously-fractured surface related with crystalline regions. Silva et al. (2016) reported WPI films with a continuous smooth surface and homogeneous structure. For the cross-section morphology, Fig. 5D (CH), Fig. 5E (WPI-6) and Fig. 5F (CH/WPI) films showed similar morphology
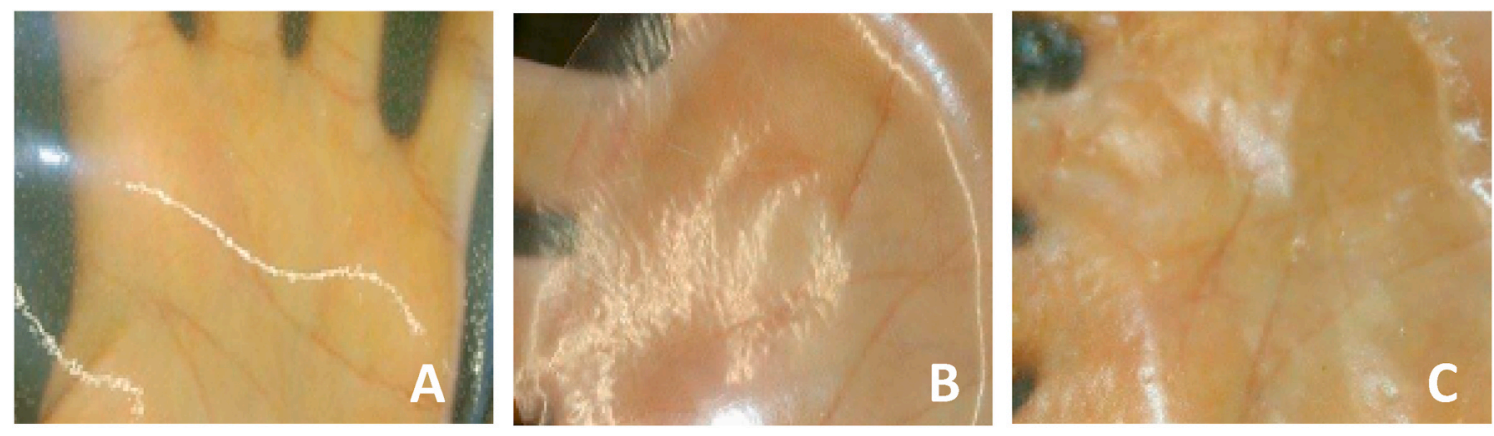

Fig. 4. Photographs of films composed by $\mathrm{CH} 3 \%(\mathrm{w} / \mathrm{w})$, WPI- 6 prepared at $5 \%(\mathrm{w} / \mathrm{w})$, and CH/WPI coacervate with mass ratio of $0.1: 1$ (w/w). 
Table 2

Solubility and optical properties for the films composed by $\mathrm{CH} 3 \%(\mathrm{w} / \mathrm{w})$, WPI-6 prepared at 5\% (w/w), and CH/WPI mass ratio of $0.1: 1$ (w/w) ${ }^{\mathrm{a}}$.

\begin{tabular}{|c|c|c|c|c|c|c|}
\hline \multirow[t]{3}{*}{ Films } & \multirow[t]{3}{*}{ Solubility in water (\%) } & \multicolumn{5}{|c|}{ Optical propriety } \\
\hline & & \multicolumn{4}{|l|}{ Color } & \multirow[t]{2}{*}{ Opacity (\%) } \\
\hline & & $a^{*}$ & $b^{*}$ & $L^{*}$ & $\Delta E$ & \\
\hline $\mathrm{CH}$ & $41.82 \pm 1.20^{c}$ & $-1.32 \pm 0.25^{\mathrm{b}}$ & $9.46 \pm 2.02^{\mathrm{a}}$ & $96.91 \pm 1.29^{\mathrm{a}, \mathrm{b}}$ & $7.98 \pm 2.07^{\mathrm{a}}$ & $14.66 \pm 1,14^{\mathrm{a}}$ \\
\hline WPI-6 & $100^{\mathrm{a}}$ & $1.33 \pm 0.02^{\mathrm{a}}$ & $-4.78 \pm 0.29^{b}$ & $99.8 \pm 0.15^{\mathrm{a}}$ & $7.19 \pm 0.31^{\mathrm{a}}$ & $12.85 \pm 0.65^{\mathrm{b}}$ \\
\hline $\mathrm{CH} / \mathrm{WPI}$ & $14.58 \pm 0.94^{b}$ & $-0.85 \pm 0.13^{\mathrm{b}}$ & $9.34 \pm 0.65^{\mathrm{a}}$ & $92.94 \pm 0.77^{\mathrm{b}}$ & $8.89 \pm 0.76^{\mathrm{a}}$ & $14.58 \pm 0.94^{\mathrm{a}}$ \\
\hline
\end{tabular}

a Means with the same letter, in the same column, did not differ significantly ( $\mathrm{p} \leq 0.05$ ), according to the Tukey test.

Table 3

GAB parameters for the films composed by $\mathrm{CH} 3 \%(\mathrm{w} / \mathrm{w})$, WPI-6 prepared at $5 \%$ $(\mathrm{w} / \mathrm{w})$ and $\mathrm{CH} / \mathrm{WPI}$ mass ratio of $0.1: 1(\mathrm{w} / \mathrm{w})^{* *}$.

\begin{tabular}{lllll}
\hline Films & $C$ & $k$ & $X_{O}$ & $R^{2}$ \\
\hline CH & 1.183 & 0.937 & 0.217 & 0.996 \\
WPI-6 & 1.095 & 0.986 & 0.137 & 0.998 \\
CH/WPI & 1.697 & 0.978 & 0.089 & 0.996 \\
\hline
\end{tabular}

with smooth surface without phase segregation and absences of cracks and grooves, which are desired characteristics for edible films applications in food products.

\subsection{FTIR analysis}

FTIR analyses were used to evaluate the differences in the functional groups of the produced films and to investigate possible interactions between the components of composite CH/WPI film. The FTIR profile obtained for CH, WPI-6, WPI-7 and CH/WPI films are shown in Fig. 6. The absorption intensities of all samples were normalized with respect to the intensity of the highest band in order to evaluate the differences between the peak intensity in the specific region of wavenumber. The FTIR spectrum of $\mathrm{CH}$ film indicated broad band in the range from $\sim 3737$ to $3000 \mathrm{~cm}^{-1}$ and centred at around $\sim 3280 \mathrm{~cm}^{-1}$ as result of stretching vibrations of O-H and N-H groups. The two weak peaks at $\sim 3937 \mathrm{~cm}^{-1}$ and $\sim 3882 \mathrm{~cm}^{-1}$ indicate the $\mathrm{C}-\mathrm{H}$ stretching, $\sim 1566 \mathrm{~cm}^{-1}$ corresponding to the amide II band $(-\mathrm{C}=\mathrm{O}$ vibration and $\mathrm{N}-\mathrm{H}$ bending vibration corresponding to the $\mathrm{NH}_{3}^{+}$protonated amide group), $\sim 1408$ $\mathrm{cm}^{-1}$ (-OH and $-\mathrm{CH}$ vibrations) and $1033 \mathrm{~cm}^{-1}$ (C-O stretching vibration). The intensity of the characteristic amide I band (at $1655 \mathrm{~cm}^{-1}$ attributed to $-\mathrm{C}=\mathrm{O}$ vibration) was very low, which indicate interaction between the plasticizer glycerol with $\mathrm{CH}$ molecules (Matet, Heuzey, Pollet, Ajji, \& Avérous, 2013). Similar spectral had been described previously for CH films (Galvis-Sánchez, Castro, Biernacki, Gonçalves, \& Souza, 2018).

Similar FTIR spectra were observed for WPI-6 and WPI-7 films, namely a broad band in the range from $\sim 3737$ to $3000 \mathrm{~cm}^{-1}$ due to the vibrations of $\mathrm{O}-\mathrm{H}$ and $\mathrm{N}-\mathrm{H}$ groups, $\sim 1628 \mathrm{~cm}^{-1}$ corresponding to amide I band ( $-\mathrm{C}=\mathrm{O}$ vibration) and $\sim 1535 \mathrm{~cm}^{-1}$ due to amide II band $(-\mathrm{C}=\mathrm{O}$ and $\mathrm{C}-\mathrm{N}$ stretching). The band at $1033 \mathrm{~cm}^{-1}$ (C-O stretching vibration) results as the influence of the plasticizer glycerol in the both films, and the peak obtained at $1240 \mathrm{~cm}^{-1}$ is an indicator of alfa-helix strands of
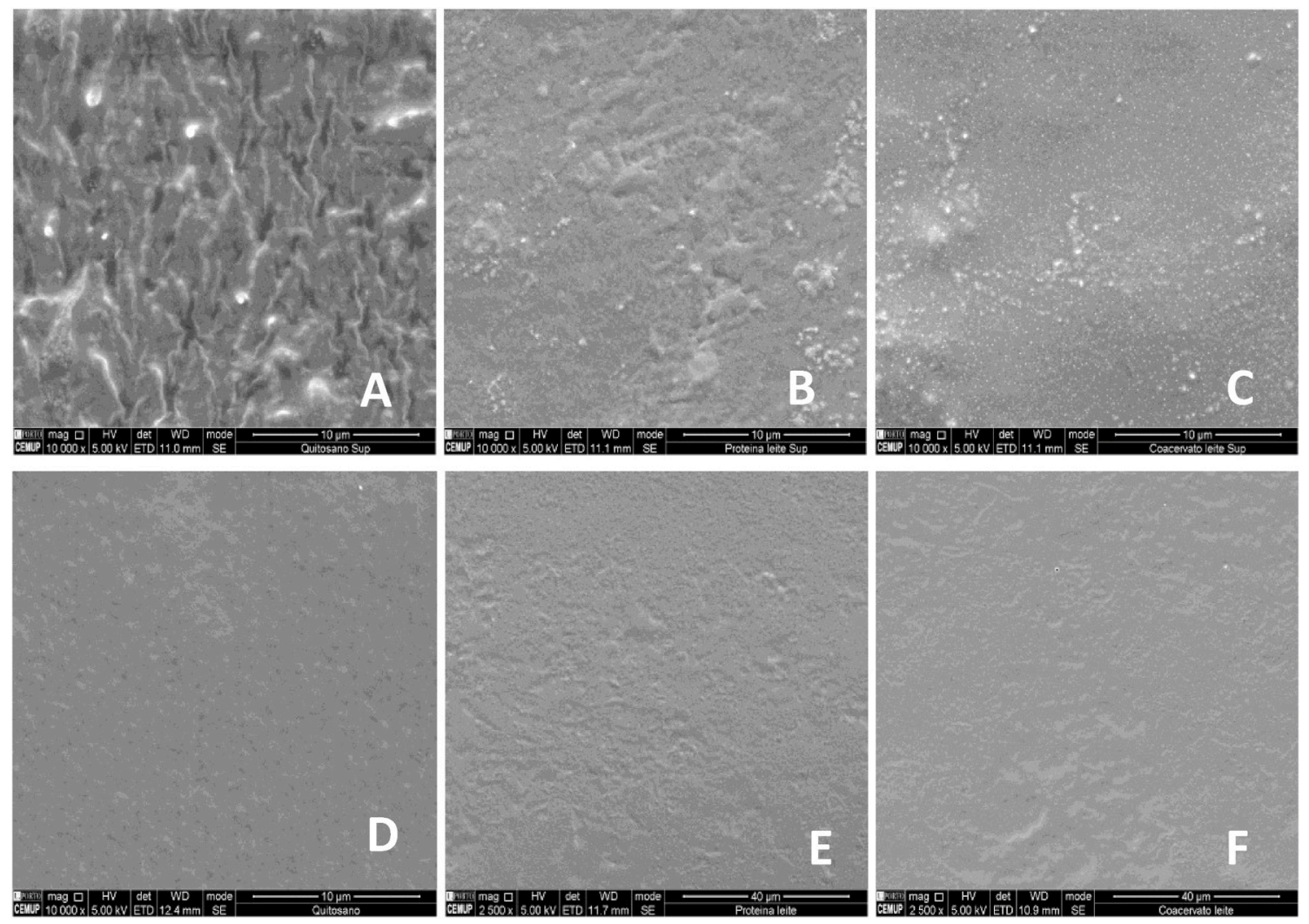

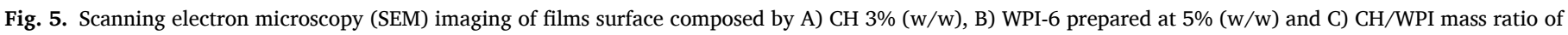

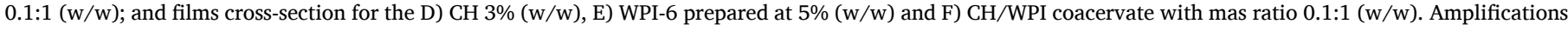
of $\mathrm{x} 10000$. The accelerating voltage was $5 \mathrm{kV}$ and working distance $15 \mathrm{~mm}$ in all cases. 


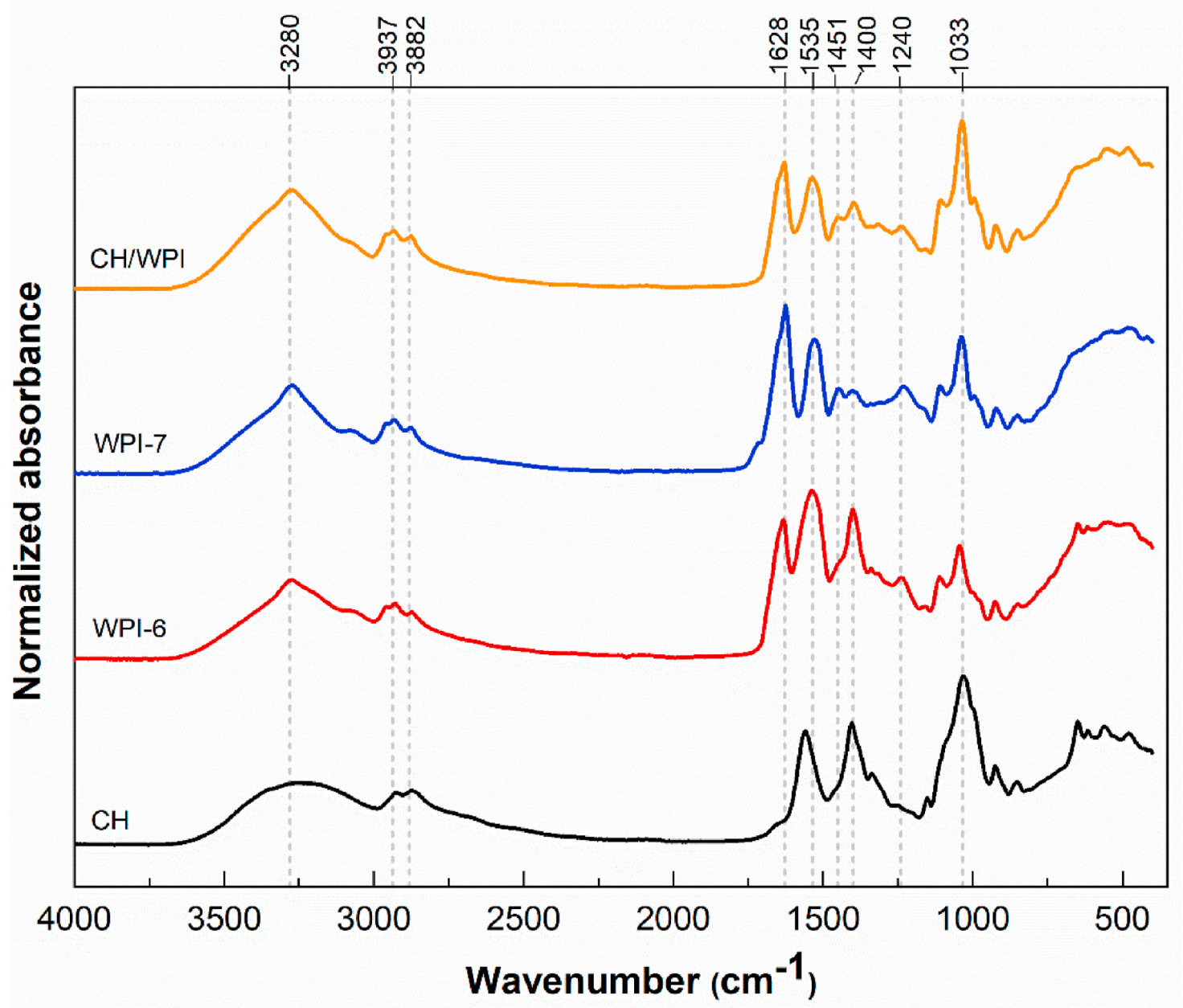

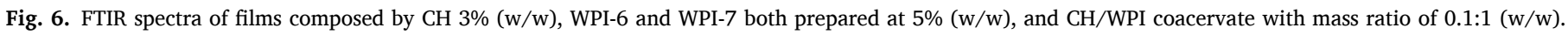

the proteins (Mohammadi, Mirabzadeh, Shahvalizadeh, \& Hamishehkar, 2020). WPI-7 film showed high peaky intensity at $1400 \mathrm{~cm}^{-1}$ indicating that the carboxyl group vibrational band with ionized groups $\left(\mathrm{COO}^{-}\right)$capable to interact with amino groups $\left(\mathrm{NH}_{3}^{+}\right)$of $\mathrm{CH}$. Similar results were reported in other studies (Böcker, Wubshet, Lindberg, \& Afseth, 2017; Singh, Suri, Tiwary, \& Rana, 2012). However, the peak of $1400 \mathrm{~cm}^{-1}$ was practically not visible for WPI-7 film, which may suggest conformational changes and reorganization of its denatured globular proteins. WPI-7 film also showed higher band intensity than WPI-6 film at $1628 \mathrm{~cm}^{-1}$ due to the formation of intermolecular $\beta$-sheet structure promoted by the denaturation of its proteins (Farrokhi, Badii, Ehsani, \& Hashemi, 2019). According to van de Weert, Haris, Hennink, and Crommelin (2001) the amide I band is originated from intermolecular antiparallel $\beta$-sheet formation, and usually the band in the region of $1620-1630 \mathrm{~cm}^{-1}$ is much more intense.

For CH/WPI film, the characteristic FTIR spectrum of WPI are dominated in combination with the spectra of $\mathrm{CH}$ due to the formation of a composite film with concentration of WPI higher than $\mathrm{CH}$. However, a decreased in the intensity of the band at $1535 \mathrm{~cm}^{-1}$ is observed for $\mathrm{CH} /$ WPI film when compared with WPI-6 film, probably caused by the electrostatic interaction between the positive amino groups $\left(\mathrm{NH}_{3}^{+}\right)$of $\mathrm{CH}$ and negative carboxyl groups $\left(-\mathrm{COO}^{-}\right)$of WPI. This chance in the carbonyl-amide region suggest existence of electrostatic interaction between the amino groups $\left(\mathrm{NH}_{3}^{+}\right)$and carboxyl groups $\left(-\mathrm{COO}^{-}\right)$(Espinosa-Andrews et al., 2010).

$\mathrm{CH} /$ WPI film presented decrease in the peaky intensity at $1400 \mathrm{~cm}^{-1}$ in comparison of WPI-6 films, indicating interactions between ionized groups $\left(\mathrm{COO}^{-}\right)$of WPI and amino groups $\left(\mathrm{NH}_{3}^{+}\right)$of $\mathrm{CH}$. However, the low peak intensity obtained at $1400 \mathrm{~cm}^{-1}$ for CH/WPI film indicate that not all proteins present in solution was capable to interact with $\mathrm{CH}$ during the process of complex coacervation. This result corroborates with the finding reported by Tavares and Noreña (2019), that demonstrated complex of $\mathrm{CH} / \mathrm{WPI}$ at ratio of $0.1: 1(\mathrm{w} / \mathrm{w})$ with coacervate yield ranged from $\sim 60$ to $70 \%$ for complex coacervation between WPI and $\mathrm{CH}$ with degree of deacetylation of 83,94 and $96 \%$.

The intensity of the broad band at around $\sim 3737$ to $3000 \mathrm{~cm}^{-1}$ for $\mathrm{CH} /$ WPI film was higher when compared with obtained for WPI-6 and $\mathrm{CH}$ films, indicating enhanced of hydrogen bonding in the WPI/CH film. Similar results were reported by Huang, Sun, Xiao, and Yang (2012) for complex coacervation of soybean protein isolate and chitosan. Alizadeh-Sani, Khezerlou, and Ehsani (2018) showed that the available peak at $3400 \mathrm{~cm}^{-1}$ became wider when the cellulose nanofiber was incorporated into WPI composite film. These results indicate that the hydrogen bonding and electrostatic interactions were involved in the formation of the complex coacervate of $\mathrm{CH} / \mathrm{WPI}$.

\subsubsection{DSC analysis}

The thermal properties of films are important factors for industrial applications, as packaging materials are often heated during the production, storage and processing of foods (Fernandes et al., 2020). DSC analyses for $\mathrm{CH}$, WPI-6, WPI-7 and CH/WPI films were performed to understand their thermal behavior. Fig. 7 shows the DSC curves of $\mathrm{CH}$, WPI-6, WPI-7 and CH/WPI films. The thermograms of the all films showed endothermic peaks, representing the typical behaviour of this 
kind of systems. Endothermic thermograms of $\mathrm{CH}$ films exhibited one wide main peak $\left(142{ }^{\circ} \mathrm{C}\right)$ that could be related with the $\alpha$-relaxation of chitosan chain and one phase transition temperature process at temperature of $233^{\circ} \mathrm{C}$, that could be related with start of chitosan' structure degradation. Similar results were reported by Peng, Wang, Shi, Chen, and Zhang (2020) for chitosan films plasticized with glycerol. The authors reported that the endothermic peak at $162{ }^{\circ} \mathrm{C}$ corresponds to the $\alpha$-relaxation of chitosan chain and the phase transition temperature, detected at $271.2{ }^{\circ} \mathrm{C}$, was associated with decomposition of the polysaccharide backbone. The difference in the value of the endothermic main peak and phase transition between the results can be associated with films formulations methodology, films conditioning, plasticizers and others important parameters such as molecular weight and deacetylation degree of chitosan used in both works.

The WPI-7 film also showed three endothermic peaks at 112, 188 and $215{ }^{\circ} \mathrm{C}$. The shape of the obtained calorimetric curve is in good agreement with previously reported ones (Hernandez-Izquierdo, Reid, McHugh, Berrios, \& Krochta, 2008). Moreover, the last endothermic peak was similar to those reported by Kim and Ustunol (2001), that indicate the degradation of whey proteins at $241^{\circ} \mathrm{C}$. Similarly, for WPI- 6 film, the thermal changes occurs in three stages at 111,160 and $196{ }^{\circ} \mathrm{C}$. Interesting, the last endothermic peak was detected at a lower temperature than that one observed for WPI-7 $\left(215{ }^{\circ} \mathrm{C}\right)$, mainly due to the previously denaturation of its whey proteins components by heat treatment.

The DSC thermogram of the CH/WPI film was very similar to WPI- 6 film, which is in accordance with the coacervate composition, though slightly shifted into higher temperatures, indicating eventually higher thermal stability. Two thermal events with endothermic main peaks at 111 and $208^{\circ} \mathrm{C}$ were observed. The second endotherm peak for $\mathrm{CH} / \mathrm{WPI}$ was less depth and shifted tip centre, indicating the formation of new network structures due to the hydrogen bond and electrostatic interactions between negatively charged whey proteins and positively charged $\mathrm{CH}$. This indicated that the incorporation of a small amount of $\mathrm{CH}$ to form complex coacervate with WPI had a significant influence on the thermal stabilities of the composite CH/WPI film. Further, in full agreement with chitosan degradation, the small peak tail at temperatures nearly at $231^{\circ} \mathrm{C}$ may indicate that the chitosan polymer is starting to degrade.

\section{Conclusion}

The formulation of films containing two biopolymers under coacervation conditions improved the characteristics of the films due to the synergistic effects between the biopolymers. Cryo-SEM analysis proved that a small amount of chitosan in the polymeric matrix of the protein improved its structure, increasing the cohesion of the biopolymers and consequent homogeneity. The organization, mesh size, arrangement, porous structure formation and composition of the biopolymers in the polymer matrix influence the physical and chemical properties of edible films and coatings. All the films presented suitable morphological aspects, transparency and formation of a homogeneous structure with well-defined interactions between biopolymers. The composite films produced by complex coacervation reveled different properties that can be interesting for food applications, including a stronger network structure, higher tensile strength, lower water vapor permeability and lower solubility in comparison to the mono-component WPI and chitosan films. In this context, considering coacervation as an additional available technique for film formation allows a wider range of WVP and mechanical properties that can be tuned to cover different applications in the food preservation and packaging technology.

\section{CRediT authorship contribution statement}

Loleny Tavares: Conceptualization, Methodology, Investigation, Formal analysis, Data curation, Writing - original draft, Writing - review \& editing. Hiléia K.S. Souza: Conceptualization, Methodology, Investigation, Formal analysis, Data curation, Writing - original draft, Writing - review \& editing. Maria Pilar Gonçalves: Conceptualization, Methodology, Investigation, Data curation, Formal analysis, Writing -

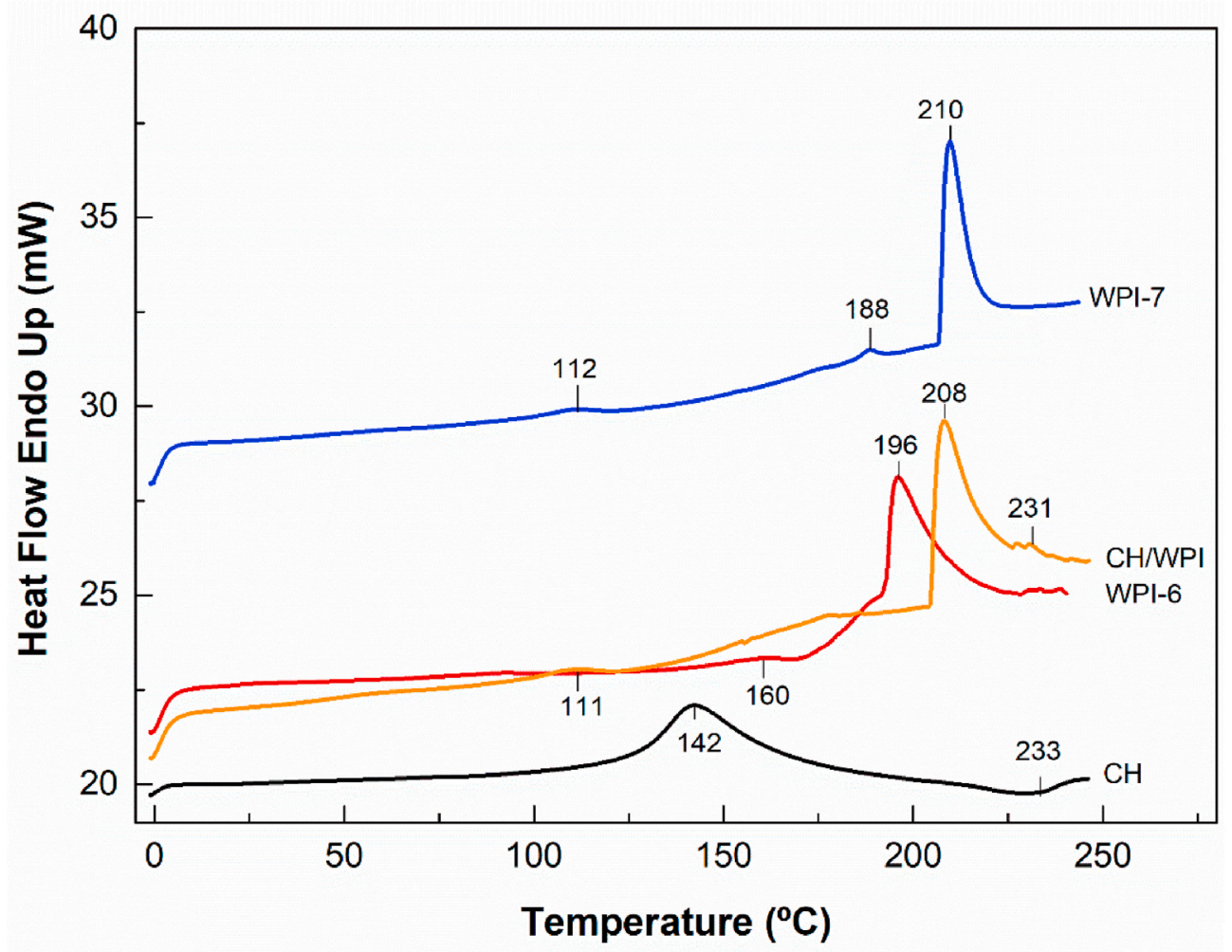

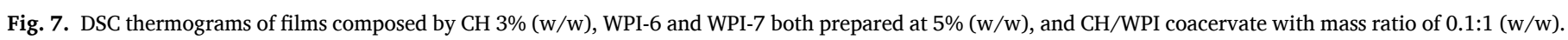


original draft, Writing - review \& editing, Supervision. Cristina M.R. Rocha: Conceptualization, Methodology, Investigation, Data curation, Formal analysis, Writing - original draft, Writing - review \& editing, Supervision.

\section{Declaration of competing interest}

The authors declare that they have no known competing financial interests or personal relationships that could have appeared to influence the work reported in this paper.

\section{Acknowledgements}

This work was supported by the Portuguese Foundation for Science and Technology (FCT) under the scope of the strategic funding of UID/ BIO/04469/2020 and UID/QUI/50006/2020 units; the work was also supported by BioTecNorte operation (NORTE-01-0145-FEDER-000004) funded by the European Regional Development Fund under the scope of Norte 2020 - Programa Operacional Regional do Norte.

\section{References}

Alizadeh-Sani, M., Ehsani, A., Moghaddas Kia, E., \& Khezerlou, A. (2019). Microbial gums: Introducing a novel functional component of edible coatings and packaging. Applied Microbiology and Biotechnology, 103(17), 6853-6866.

Alizadeh-Sani, M., Khezerlou, A., \& Ehsani, A. (2018). Fabrication and characterization of the bionanocomposite film based on whey protein biopolymer loaded with TiO2 nanoparticles, cellulose nanofibers and rosemary essential oil. Industrial Crops and Products, 124, 300-315.

Anderson, R. B. (1946). Modifications of the Brunauer, Emmett and Teller Equation 1. Journal of the American Chemical Society, 68(4), 686-691.

ASTM. (1995). Standard test methods for water vapor transmission of materials. E96-95. In Annual book of ASTM standards American society for testing and materials (pp. 406-413). Philadelphia: American Society for Testing Materials.

Baron, R. D., Pérez, L. L., Salcedo, J. M., Córdoba, L. P., \& Sobral, P. J. D. A. (2017). Production and characterization of films based on blends of chitosan from blue crab (Callinectes sapidus) waste and pectin from Orange (Citrus sinensis Osbeck) peel. International Journal of Biological Macromolecules, 98, 676-683.

Bastos, D. S., Barreto, B. N., Souza, H. K., Bastos, M., Rocha-Leão, M. H. M., Andrade, C. T., et al. (2010). Characterization of a chitosan sample extracted from Brazilian shrimps and its application to obtain insoluble complexes with a commercial whey protein isolate. Food Hydrocolloids, 24(8), 709-718.

Bastos, D. D. S., Gonçalves, M. D. P., Andrade, C. T. D., Araújo, K. G. D. L., \& Rocha Leão, M. H. M. D. (2012). Microencapsulation of cashew apple (Anacardium occidentale, L.) juice using a new chitosan-commercial bovine whey protein isolate system in spray drying. Food and Bioproducts Processing, 90(4), 683-692.

Böcker, U., Wubshet, S. G., Lindberg, D., \& Afseth, N. K. (2017). Fourier-transform infrared spectroscopy for characterization of protein chain reductions in enzymatic reactions. Analyst, 142, 2812-2818.

Boer, J. H. d (1968). The dynamical character of adsorption. London: Oxford University Press.

Bourtoom, T. (2008). Edible films and coatings: Characteristics and properties. International Food Research Journal, 15(3), 237-248.

Cazón, P., Velazquez, G., Ramírez, J. A., \& Vázquez, M. (2017). Polysaccharide-based films and coatings for food packaging: A review. Food Hydrocolloids, 68, 136-148.

Chillo, S., Flores, S., Mastromatteo, M., Conte, A., Gerschenson, L., \& Del Nobile, M. A. (2008). Influence of glycerol and chitosan on tapioca starch-based edible film properties, Journal of Food Engineering, 88(2), 159-168.

Córdoba, L. J. P., \& Sobral, P. J. (2017). Physical and antioxidant properties of films based on gelatin, gelatin-chitosan or gelatin-sodium caseinate blends loaded with nanoemulsified active compounds. Journal of Food Engineering, 213, 47-53.

Dehghani, S., Hosseini, S. V., \& Regenstein, J. M. (2018). Edible films and coatings in seafood preservation: A review. Food Chemistry, 240, 505-513.

Di Pierro, P., Chico, B., Villalonga, R., Mariniello, L., Damiao, A. E., Masi, P., et al. (2006). Chitosan-whey protein edible films produced in the absence or presence of transglutaminase: analysis of their mechanical and barrier properties. Biomacromolecules, 7(3), 744-749.

Di Pierro, P., Sorrentino, A., Mariniello, L., Giosafatto, C. V. L., \& Porta, R. (2011). Chitosan/whey protein film as active coating to extend Ricotta cheese shelf-life. Lebensmittel-Wissenschaft und -Technologie- Food Science and Technology, 44(10), 2324-2327.

Ducel, V., Richard, J., Saulnier, P., Popineau, Y., \& Boury, F. (2004). Evidence and characterization of complex coacervates containing plant proteins: Application to the microencapsulation of oil droplets. Colloids and Surfaces A: Physicochemical and Engineering Aspects, 232(2), 239-247.

Ebrahimi, S. E., Koocheki, A., Milani, E., \& Mohebbi, M. (2016). Interactions between Lepidium perfoliatum seed gum - grass pea (Lathyrus sativus) protein isolate in composite biodegradable film. Food Hydrocolloids, 54, 302-314.
Eghbal, N., Yarmand, M. S., Mousavi, M., Degraeve, P., Oulahal, N., \& Gharsallaoui, A. (2016). Complex coacervation for the development of composite edible films based on LM pectin and sodium caseinate. Carbohydrate Polymers, 151, 947-956.

Espinosa-Andrews, H., Sandoval-Castilla, O., Vázquez-Torres, H., Vernon-Carter, E. J., \& Lobato-Calleros, C. (2010). Determination of the gum Arabic-chitosan interactions by Fourier transform infrared spectroscopy and characterization of the microstructure and rheological features of their coacervates. Carbohydrate Polymers, $79(3), 541-546$.

Farrokhi, F., Badii, F., Ehsani, M. R., \& Hashemi, M. (2019). Functional and thermal properties of nanofibrillated whey protein isolate as functions of denaturation temperature and solution $\mathrm{pH}$. Colloids and Surfaces A: Physicochemical and Engineering Aspects, 583, 124002

Fernandes, L. M., Guimarães, J. T., Silva, R., Rocha, R. S., Coutinho, N. M. Balthazar, C. F., et al. (2020). Whey protein films added with galactooligosaccharide and xylooligosaccharide. Food Hydrocolloids, 104, 105755.

Ferreira, A. R., Alves, V. D., \& Coelhoso, I. M. (2016). Polysaccharide-based membranes in food packaging applications. Membranes, 6(2), 22.

Ferreira, C. O., Nunes, C. A., Delgadillo, I., \& Lopes-da-Silva, J. A. (2009). Characterization of chitosan-whey protein films at acid pH. Food Research International, 42(7), 807-813.

Galus, S., \& Lenart, A. (2013). Development and characterization of composite edible films based on sodium alginate and pectin. Journal of Food Engineering, 115(4), 459-465.

Galvis-Sánchez, A. C., Castro, M. C. R., Biernacki, K., Gonçalves, M. P., \& Souza, H. K. S. (2018). Natural deep eutectic solvents as green plasticizers for chitosan thermoplastic production with controlled/desired mechanical and barrier properties. Food Hydrocolloids, 82, 478-489.

Gounga, M. E., Xu, S. Y., \& Wang, Z. (2007). Whey protein isolate-based edible films as affected by protein concentration, glycerol ratio and pullulan addition in film formation. Journal of Food Engineering, 83(4), 521-530.

Hernandez-Izquierdo, V. M., Reid, D. S., McHugh, T. H., De, J., Berrios, J., \& Krochta, J. M. (2008). Thermal transitions and Extrusion of glycerol-plasticized whey protein mixtures. Journal of Food Science, 73(4), E169-E175.

Homez-Jara, A., Daza, L. D., Aguirre, D. M., Muñoz, J. A., Solanilla, J. F., \& Váquiro, H. A. (2018). Characterization of chitosan edible films obtained with various polymer concentrations and drying temperatures. International Journal of Biological Macromolecules, 113, 1233-1240.

Hosseini, S. F., \& Gómez-Guillén, M. C. (2018). A state-of-the-art review on the elaboration of fish gelatin as bioactive packaging: Special emphasis on nanotechnology-based approaches. Trends in Food Science \& Technology, 79, 125-135.

Huang, G. Q., Sun, Y. T., Xiao, J. X., \& Yang, J. (2012). Complex coacervation of soybean protein isolate and chitosan. Food Chemistry, 135, 534-539.

Jho, Y., Yoo, H. Y., Lin, Y., Han, S., \& Hwang, D. S. (2017). Molecular and structural basis of low interfacial energy of complex coacervates in water. Advances in Colloid and Interface Science, 239, 61-73.

Jiang, S. J., Zhang, X., Ma, Y., Tuo, Y., Qian, F., Fu, W., et al. (2016). Characterization of whey protein-carboxymethylated chitosan composite films with and without transglutaminase treatment. Carbohydrate Polymers, 153, 153-159.

Kaewprachu, P., \& Rawdkuen, S. (2016). Application of active edible film as food packaging for food preservation and pxtending shelf life. In N. Garg, S. M. AbdelAziz, \& A. Aeron (Eds.), Microbes in food and health (pp. 185-205). Cham: Springer International Publishing.

Kester, J. J., \& Fennema, O. (1986). Edible films and coatings: A review. Food Technology (USA), 40(12), 59.

Khodaei, D., Oltrogge, K., \& Hamidi-Esfahani, Z. (2020). Preparation and characterization of blended edible films manufactured using gelatin, tragacanth gum and, Persian gum. Lebensmittel-Wissenschaft und-Technologie-Food Science and Technology, 117, 108617.

Kim, S. J., \& Ustunol, Z. (2001). Thermal properties, heat sealability and seal attributes of whey protein isolate/lipid emulsion edible films. Journal of Food Science, 66(7), 985-990.

Kokoszka, S., Debeaufort, F., Lenart, A., \& Voilley, A. (2010). Water vapour permeability, thermal and wetting properties of whey protein isolate based edible films. International Dairy Journal, 20(1), 53-60.

Kurek, M., Galus, S., \& Debeaufort, F. (2014). Surface, mechanical and barrier properties of bio-based composite films based on chitosan and whey protein. Food Packaging and Shelf Life, 1(1), 56-67.

Lippolis, V., Irurhe, O., Porricelli, A. C. R., Cortese, M., Schena, R., Imafidon, T., et al (2017). Natural co-occurrence of aflatoxins and ochratoxin A in ginger (Zingiber officinale) from Nigeria. Food Control, 73, 1061-1067.

Livney, Y. D. (2010). Milk proteins as vehicles for bioactives. Current Opinion in Colloid \& Interface Science, 15(1), 73-83.

Luyt, A. S., \& Malik, S. S. (2019). 16 - can biodegradable plastics solve plastic solid waste accumulation? In S. M. Al-Salem (Ed.), Plastics to energy (pp. 403-423). William Andrew Publishing.

Matet, M., Heuzey, M. C., Pollet, E., Ajji, A., \& Avérous, L. (2013). Innovative thermoplastic chitosan obtained by thermo-mechanical mixing with polyol plasticizers. Carbohydrate Polymers, 95, 241-251.

Mohammadi, M., Mirabzadeh, S., Shahvalizadeh, R., \& Hamishehkar, H. (2020) Development of novel active packaging films based on whey protein isolate incorporated with chitosan nanofiber and nano-formulated cinnamon oil. International Journal of Biological Macromolecules, 149, 11-20.

de Morais Lima, M., Carneiro, L. C., Bianchini, D., Dias, A. R. G., Zavareze, E.d. R., Prentice, C., et al. (2017). Structural, thermal, physical, mechanical, and barrie 
properties of chitosan films with the addition of xanthan gum. Journal of Food Science, 82(3), 698-705.

Mujtaba, M., Morsi, R. E., Kerch, G., Elsabee, M. Z., Kaya, M., Labidi, J., et al. (2019). Current advancements in chitosan-based film production for food technology; A review. International Journal of Biological Macromolecules, 121, 889-904.

Muxika, A., Etxabide, A., Uranga, J., Guerrero, P., \& de la Caba, K. (2017). Chitosan as a bioactive polymer: Processing, properties and applications. International Journal of Biological Macromolecules, 105, 1358-1368.

Ojagh, S. M., Rezaei, M., Razavi, S. H., \& Hosseini, S. M. H. (2010). Development and evaluation of a novel biodegradable film made from chitosan and cinnamon essential oil with low affinity toward water. Food Chemistry, 122(1), 161-166.

Peng, Y., Wang, Q., Shi, J., Chen, Y., \& Zhang, X. (2020). Optimization and release evaluation for tea polyphenols and chitosan composite films with regulation of glycerol and Tween. Food Science and Technology, 40(1), 162-170.

Pérez-Gago, M. B., Nadaud, P., \& Krochta, J. M. (1999). Water vapor permeability, solubility, and tensile properties of heat-denatured versus native whey Protein films. Journal of Food Science, 64(6), 1034-1037.

Ramos, Ó. L., Reinas, I., Silva, S. I., Fernandes, J. C., Cerqueira, M. A., Pereira, R. N., et al. (2013). Effect of whey protein purity and glycerol content upon physical properties of edible films manufactured therefrom. Food Hydrocolloids, 30(1), 110-122.

Rhim, J. W., Gennadios, A., Weller, C. L., Carole, C., \& Hanna, M. A. (1998). Soy protein isolate-dialdehyde starch films 1. Industrial Crops and Products, 8(3), 195-203.

Rocha, C. M. R., Souza, H. K. S., Magalhães, N. F., Andrade, C. T., \& Gonçalves, M. P. (2014). Rheological and structural characterization of agar/whey proteins insoluble complexes. Carbohydrate Polymers, 110, 345-353.

Salgado, P. R., Ortiz, C. M., Musso, Y. S., Di Giorgio, L., \& Mauri, A. N. (2015). Edible films and coatings containing bioactives. Current Opinion in Food Science, 5, 86-92.

Schmitt, C., \& Turgeon, S. L. (2011). Protein/polysaccharide complexes and coacervates in food systems. Advances in Colloid and Interface Science, 167(1), 63-70.

Silva, K. S., Mauro, M. A., Gonçalves, M. P., \& Rocha, C. M. R. (2016). Synergistic interactions of locust bean gum with whey proteins: Effect on physicochemical and microstructural properties of whey protein-based films. Food Hydrocolloids, 54, 179-188.

Singh, K., Suri, R., Tiwary, A. K., \& Rana, V. (2012). Chitosan films: Crosslinking with EDTA modifies physicochemical and mechanical properties. Journal of Materials Science: Materials in Medicine, 23, 687-695.
Sousa, A. M. M., Souza, H. K. S., Latona, N., Liu, C.-K., Gonçalves, M. P., \& Liu, L. (2014). Choline chloride based ionic liquid analogues as tool for the fabrication of agar films with improved mechanical properties. Carbohydrate Polymers, 111, 206-214.

Souza, H. K., Bai, G., Gonçalves, M. P., \& Bastos, M. (2009). Whey protein isolate-chitosan interactions: A calorimetric and spectroscopy study. Thermochimica Acta, 495(1), 108-114.

Souza, H. K., Campiña, J. M., Sousa, A. M. M., Silva, F., \& Gonçalves, M. P. (2013). Ultrasound-assisted preparation of size-controlled chitosan nanoparticles: Characterization and fabrication of transparent biofilms. Food Hydrocolloids, 31(2), 227-236.

Talón, E., Trifkovic, K. T., Nedovic, V. A., Bugarski, B. M., Vargas, M., Chiralt, A., et al. (2017). Antioxidant edible films based on chitosan and starch containing polyphenols from thyme extracts. Carbohydrate Polymers, 157, 1153-1161.

Tavares, L., Barros, H. L. B., Vaghetti, J. C. P., \& Noreña, C. P. Z. (2019). Microencapsulation of garlic extract by complex coacervation using whey protein isolate/chitosan and gum Arabic/chitosan as wall materials: Influence of anionic biopolymers on the physicochemical and structural properties of microparticles. Food and Bioprocess Technology, 12(12), 2093-2106.

Tavares, L., \& Noreña, C. P. Z. (2019). Encapsulation of garlic extract using complex coacervation with whey protein isolate and chitosan as wall materials followed by spray drying. Food Hydrocolloids, 89, 360-369.

Tavares, L., \& Noreña, C. P. Z. (2021). Characterization of the physicochemical, structural and thermodynamic properties of encapsulated garlic extract in multilayer wall materials. Powder Technology, 378, 388-399.

Tavassoli-Kafrani, E., Shekarchizadeh, H., \& Masoudpour-Behabadi, M. (2016). Development of edible films and coatings from alginates and carrageenans. Carbohydrate Polymers, 137, 360-374.

Tharanathan, R. N. (2003). Biodegradable films and composite coatings: Past, present and future. Trends in Food Science \& Technology, 14(3), 71-78.

van de Weert, M., Haris, P. I., Hennink, W. E., \& Crommelin, D. J. A. (2001). Fourier transform infrared spectrometric analysis of protein conformation: Effect of sampling method and stress factors. Analytical Biochemistry, 297, 160-169.

Xiao, Q., Lim, L. T., \& Tong, Q. (2012). Properties of pullulan-based blend films as affected by alginate content and relative humidity. Carbohydrate Polymers, 87(1), 227-234.

Zhang, W., Chen, J., Chen, Y., Xia, W., Xiong, Y. L., \& Wang, H. (2016). Enhanced physicochemical properties of chitosan/whey protein isolate composite film by sodium laurate-modified TiO2 nanoparticles. Carbohydrate Polymers, 138, 59-65. 